Revista Brasileira de Cartografia

ISSN 1808-0936 | https://doi.org/10.14393/revbrascartogr

Sociedade Brasileira de Cartografia, Geodésia, Fotogrametria e Sensoriamento Remoto

\title{
Análise Temática e Conceitual de Mapas Geomorfológicos: A Transcrição Gráfica da Complexidade do Relevo
}

\author{
Thematic and Conceptual Analysis of Geomorphological Maps: The Graphic \\ Transcription of the Land Surface Complexity
}

Ricardo Michael Pinheiro Silveira ${ }^{1}$ e Claudinei Taborda da Silveira ${ }^{2}$

1 Instituto Federal do Paraná (Campus Curitiba), Curitiba, Brasil. ricardomichaelps@gmail.com.

ORCID: https://orcid.or/0000-0002-5664-7079

2 Universidade Federal do Paraná, Departamento de Geografia, Curitiba, Brasil. claudineits @ ufpr.br.

ORCID: https://orcid.org/0000-0001-6289-6306

Resumo: As representações do relevo, transcritas pela cartografia geomorfológica, suscitam discussões historicamente pautadas pela complexidade multiescalar das feições e processos vinculados à modelagem da superfície. Sobretudo desde a década de 1950, considera-se que um mapa geomorfológico deve representar, de modo integrado, informações referentes à dimensão (morfometria), aspecto (morfografia), origem (morfogênese), processos atuantes (morfodinâmica) e a idade (morfocronologia) do relevo. No âmbito dos preceitos mencionados, este trabalho objetivou analisar mapas geomorfológicos de distintos recortes espaciais, escalas, datas e contextos de relevo sob a perspectiva teorética, que compreende conceitos e pressupostos da cartografia geomorfológica, e temática, que contempla a implantação gráfica e construção da legenda. Foram analisados 57 mapas geomorfológicos, categorizados em: mapeamentos nacionais, de regiões (recortes geográficos específicos) e de estados do Brasil. Adotou-se como critério de análise temática as variáveis visuais, no âmbito da semiologia gráfica, para cada aspecto geomorfológico elementar potencialmente mapeado: morfometria, morfografia, morfogênese, morfodinâmica e morfocronologia. Os resultados evidenciaram que os mapas nacionais possuem sofisticados sistemas de legenda, os mapas de regiões atendem demandas especializadas e os mapas estaduais priorizam o mapeamento de grandes unidades morfográficas. $56 \%$ dos mapas analisados representaram todos os aspectos geomorfológicos requeridos, ainda que alguns de modo implícito. Individualmente, a morfogênese $(61,4 \%)$ e a morfografia $(52,6 \%)$ foram os aspectos mais enfatizados nos mapas analisados. Conclui-se, por fim, que as concepções multiescalares têmporo-espaciais e teórico-metodológicas intrínsecas aos mapeamentos, além das características do relevo local, são fatores que dificultam padronizações e replicações de legendas.

Palavras-chave: Cartografia geomorfológica. Mapeamento do relevo. Cartografia temática. Geomorfologia.

\begin{abstract}
The representations of the land surface, transcribed by geomorphological cartography, raise discussions historically guided by the multiscale complexity of the features and processes linked to the modeling of the surface. Especially since the 1950s, it is considered that a geomorphological map must represent, in an integrated way, information regarding the land surface dimension (morphometry), aspect (morphography), origin (morphogenesis), active processes (morphodynamics) and age (morphochronology). Within the scope of the aforementioned precepts, this study aimed to analyze geomorphological maps of different areas, scales, dates and geomorphological contexts under the theoretical (concepts and assumptions of geomorphological mapping) and thematic (graphical implantation and construction of the legend). 57 geomorphological maps were analyzed, categorized into: national mappings, regions (specific areas) and states in Brazil. Thematic variables were adopted as the criterion for thematic analysis, within the scope of graphic semiology, for each potentially mapped elementary geomorphological aspect: morphometry, morphography, morphogenesis, morphodynamics and morphochronology. The results showed that national maps have sophisticated legend systems, maps of regions meet specialized demands and state maps prioritize the mapping of large morphographic units. $56 \%$ of the analyzed maps represented all the required geomorphological aspects, although some implicitly. Individually, morphogenesis (61.4\%) and morphography (52.6\%) were the aspects most emphasized in the analyzed maps. Finally, it is concluded that the multiscalar temporal-spatial and theoreticalmethodological conceptions intrinsic to the mappings, in addition to the characteristics of the local land surface, are factors that hinder standardization and replication of the legends.
\end{abstract}

Keywords: Geomorphological cartography. Land surface mapping. Thematic cartography. Geomorphology. 


\section{INTRODUÇÃO}

Mapas geomorfológicos constituem complexos documentos temáticos que objetivam a representação integrada da superfície terrestre sob suas diversas variáveis e dimensões constituintes, fornecendo uma descrição das formas de relevo identificadas com denominações específicas e representadas por símbolos apropriados. Conforme apontam Klimaszewski (1982), Kohler (2001), Florenzano (2008), Dramis et al. (2011) e Coltrinari (2011), o mapa geomorfológico é um complexo produto temático devido ao elevado número de informações a serem cartografadas, às subjetividades intrínsecas à interpretação dos fatos geomorfológicos e também devido às concepções têmporo-espaciais multiescalares associadas à representação do relevo.

Embora o primeiro mapa geomorfológico, propriamente dito, segundo Verstappen (2011), seja vinculado à publicação de Passarge, em 1914, somente após a Segunda Guerra Mundial a cartografia geomorfológica passou a ser notabilizada. Tal fato decorreu, notoriamente, do auxílio de fotografias aéreas que possibilitaram o desenvolvimento de estudos detalhados do relevo (em escalas 1:50.000 ou maiores) considerando as relações entre embasamento, clima e gênese das formas observadas (COLTRINARI, 2011).

As décadas de 1950 e 1960 marcaram, portanto, uma importante fase de estruturação da cartografia geomorfológica a partir de congressos internacionais que objetivaram aprofundar a discussão da temática numa perspectiva integradora. À época, os resultados sistematizados pela Subcomissão de Mapeamento Geomorfológico da União Internacional de Geografia (IGU) culminaram na realização de um manual para mapeamento geomorfológico detalhado e de média escala, publicado por Demek (1972).

Apesar das dificuldades de normatização, há um consenso, desde os mencionados congressos, que os mapas geomorfológicos devem atender seis pontos principais: i) prover uma descrição completa e objetiva das formas de relevo (morfografia); ii) incluir informações sobre suas propriedades espaciais, como dimensões, inclinação e curvatura (morfometria); iii) relatar sua origem e evolução em relação aos agentes e processos genéticos endógenos e exógenos (morfogênese), considerando também os efeitos da litologia e controle estrutural; iv) indicar a idade relativa ou absoluta das formas de relevo (morfocronologia); v) apresentar a situação de atividade do relevo e taxa de processos genéticos (morfodinâmica); vi) indicar as formações rochosas e os depósitos superficiais (DRAMIS et al., 2011).

Devido a essas especificidades apresentadas, Rodrigues (2010) argumenta que um mapa geomorfológico deve ser apoiado em critérios de representação gráfica bem definidos, a fim de otimizar a leitura e facilitar a interpretação dos fenômenos geomorfológicos. E, dentre todas as problemáticas relacionadas à representação e interpretação, a legenda é uma das questões centrais.

As legendas de mapas geomorfológicos analíticos (básicos), para Verstappen (2011), tendem a ser muito complexas pela diversidade de dados a serem incluídos nas características morfométricas, morfográficas, morfogenéticas, morfocronológicas e morfodinâmicas do relevo e, por esse motivo, os produtos cartográficos geralmente contêm grande quantidade de informações e possuem alto valor científico. Para o autor, a padronização completa da legenda só é necessária para mapeamentos de nível nacional ou internacional.

Otto et al. (2011) apresentaram uma contextualização das técnicas cartográficas e suas aplicações em mapeamento geomorfológico com foco nos principais sistemas de legendas propostos até então. Segundo os autores, para representar a complexidade do relevo, diferentes tipos de símbolos, cores e demais elementos cartográficos precisam ser organizados cuidadosamente para a obtenção de um mapa legível que expresse claramente o conteúdo proposto. Para Klimaszewski (1982), a dificuldade de padronização de legenda se deve às especificidades locais de cada mapeamento, como a influência das linhagens epistemológicas, características geomorfológicas da área, disponibilidade de dados e objetivos pretendidos.

A polissêmia, resultante das problemáticas vinculadas à legenda e às múltiplas representações têmporo-espaciais de mapas geomorfológicos remetem diretamente às questões inerentes à comunicação cartográfica. Como contraposição à comunicação polissêmica, a Semiologia Gráfica aplicada à Cartografia Temática resultou na Teoria Geral dos Signos (SILVEIRA, 2019). Para Archela (2001, p. 45), "a semiologia gráfica pode ser compreendida como um conjunto de diretrizes que orientam a elaboração de mapas temáticos com o uso de símbolos caracterizadores da informação".

A principal contribuição para o estabelecimento dessa corrente adveio de Bertin (1967), que 
considerava a Cartografia como uma linguagem universal e, portanto, monossêmica. A sistematização de uma linguagem gráfica tendo como base um sistema de símbolos gráficos com significado (expressão do conceito) e significante (expressão gráfica), de modo simultâneo, finda suprimir a ambiguidade no processo de comunicação cartográfica (DENT, 1999; SLOCUM et al., 2009).

Dessa forma, os mapas geomorfológicos diferem de outros produtos temáticos do relevo por representaram, de modo integrado, morfologia (morfometria e morfografia), morfogênese, morfocronologia e morfodinâmica. Em relação ao componente escalar, como exemplo, cita-se Dramis e Bisci (1998), que propuseram uma categorização relacionando a escala cartográfica com os segmentos mínimos e máximos mapeáveis - respectivamente, 0,2 e $40 \mathrm{~cm}$, medidos no mapa.

No Brasil, os trabalhos de mapeamento geomorfológico seguem, predominantemente, concepções hierárquicas com ênfase na representação da morfografia. Numa perspectiva sistemática e de construção metodológica, a principal contribuição em nível nacional deriva dos resultados do Projeto RADAMBRASIL, desenvolvido durante a década de 1970 e que, apesar de dispostos em escala pequena (1:1.000.000), criou um sistema de legenda aberto e flexível, que possibilitou acréscimos e adaptações em propostas subsequentes (FLORENZANO, 2008; COLTRINARI, 2011). Barbosa et al. (1984, p. 9) cita que "até 1968, a experiência acumulada no Brasil sobre mapas geomorfológicos era pequena, dispare em escalas e geralmente calcada em modelos estrangeiros".

A concepção metodológica do Projeto RADAMBRASIL foi influenciada pelos trabalhos de Ab'Saber (1964; 1969; 1998) e, posteriormente, influenciou na proposta de mapeamento de Ross (1992) - com os seis níveis taxonômicos para a classificação hierárquica do relevo, amplamente utilizada - e também do Manual Técnico de Geomorfologia, publicado pelo IBGE (2009), cuja primeira versão é datada de 1995. A estruturação da cartografia geomorfológica brasileira, nesse contexto, foi discutida por Botelho e Pelech (2019) e por Pelech et al. (2019), cujas contribuições auxiliaram a embasar a proposta de um Sistema Brasileiro de Classificação do Relevo (SBCR). O referido sistema está em fase de construção pela comunidade geomorfológica brasileira e objetiva a organização, de forma categórica, hierárquica e multiescalar, de uma taxonomia que expresse a diversidade de formas de relevo existentes no Brasil, constituindo referência para futuros mapeamentos geomorfológicos (IBGE, 2020).

Amparado na problemática supra apresentada, o presente trabalho objetivou analisar mapas geomorfológicos representativos de distintas localidades, escalas e datas para estabelecer um panorama sobre a composição da tais produtos cartográficos, contemplando, associativamente, as questões temáticas (aspectos da transcrição gráfica da informação) e geomorfológicas (aspectos conceituais acerca dos objetos).

\section{MATERIAIS E MÉTODOS}

A etapa de análise objetivou estabelecer um panorama da construção de mapas geomorfológicos sob suas diversas variáveis constituintes, sejam geomórficas ou ligadas à cartografia temática, com produtos de distintas datas (1963-2017), países, escalas e recortes. Para a avaliação categorizada foram adotados três níveis de seleção, conforme disponibilidade de mapas em periódicos, institutos de pesquisa ou publicações técnicas:

a) mapeamentos nacionais, majoritariamente derivados de projetos governamentais, que contemplam legenda padronizada e articulação sistemática;

b) mapeamentos regionais, resultantes de projetos e/ou estudos específicos, individualizados, que embora possam ter vinculação nacional não compreendem toda sua extensão;

c) mapeamentos estaduais, com a inclusão das unidades federativas do Brasil que dispõem de cartografia geomorfológica sistematizada.

A abrangência do conjunto de mapas selecionados é indicada pela Figura 1, com a representação dos países contemplados na análise. Destaca-se que nesta etapa foram selecionados documentos estritamente intitulados de mapas geomorfológicos ou cartas geomorfológicas. Produtos cartográficos denominados de mapas morfológicos, fisiográficos, mapas de unidades de relevo, unidades de paisagem e afins, mesmo contendo os elementos básicos de um mapa geomorfológico, foram desconsiderados. Segundo definição 
clássica de Doornkamp (1971), o termo "morfológico" é empregado para somente indicar determinada forma da superfície, enquanto o termo "geomorfológico" é utilizado buscando a interpretação dessa mesma forma.

Para todos os mapas selecionados, os critérios de análise seguiram duas abordagens: geomorfológica e de cartografia temática. Na primeira, buscou-se avaliar se os mapas contemplavam na sua representação os cinco elementos básicos do relevo: morfometria, morfografia, morfogênese, morfodinâmica e morfocronologia, conforme diretrizes para a cartografia geomorfológica discutidas desde o final da década de 1950 (KLIMASZEWSKI, 1982; FLORENZANO, 2008; COLTRINARI, 2011; VERSTAPPEN, 2011).

Figura 1 - Abrangência dos mapas geomorfológicos analisados.

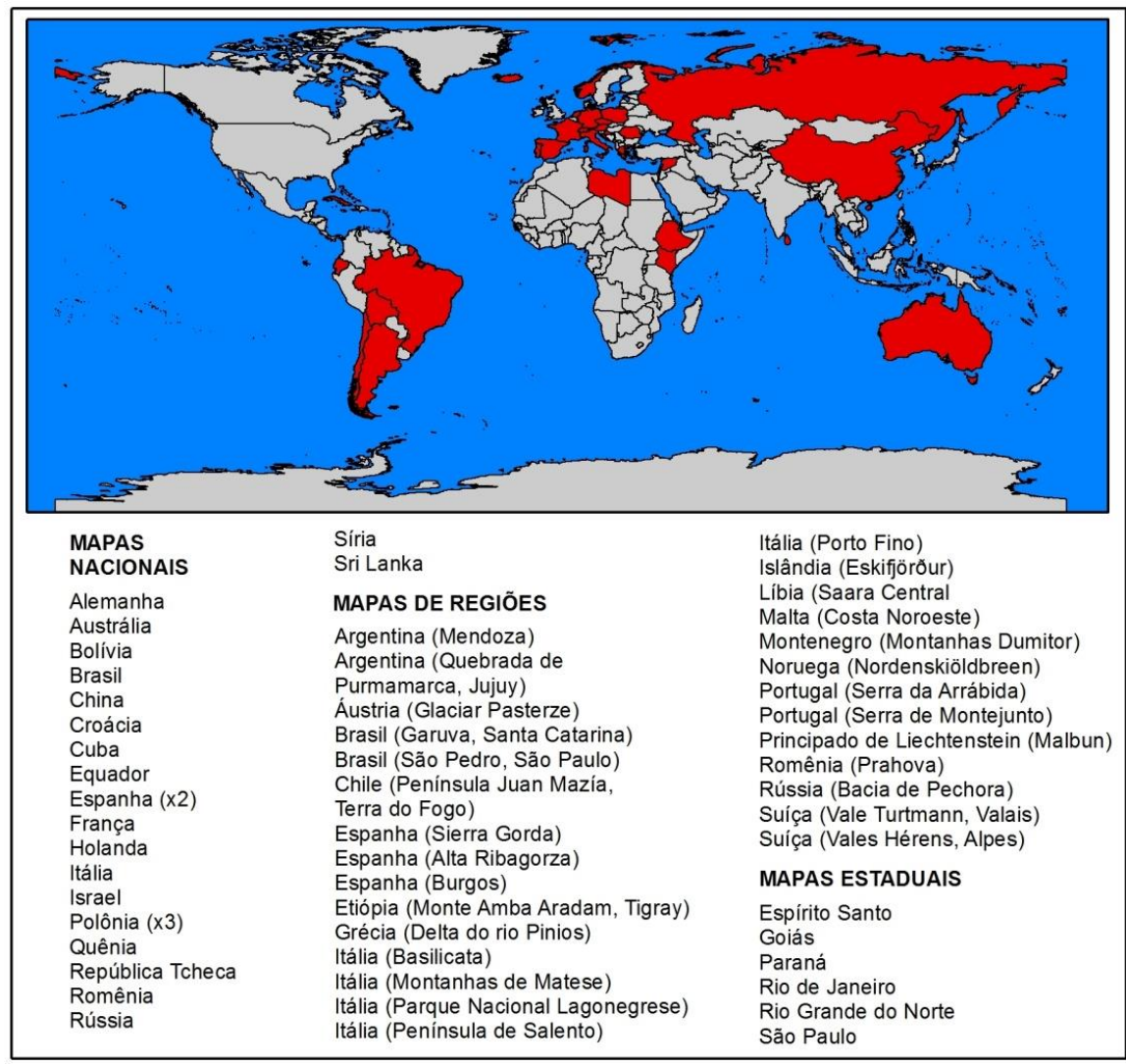

Fonte: Os autores (2021).

Figura 2 - Variáveis visuais e seus modos de implantação.

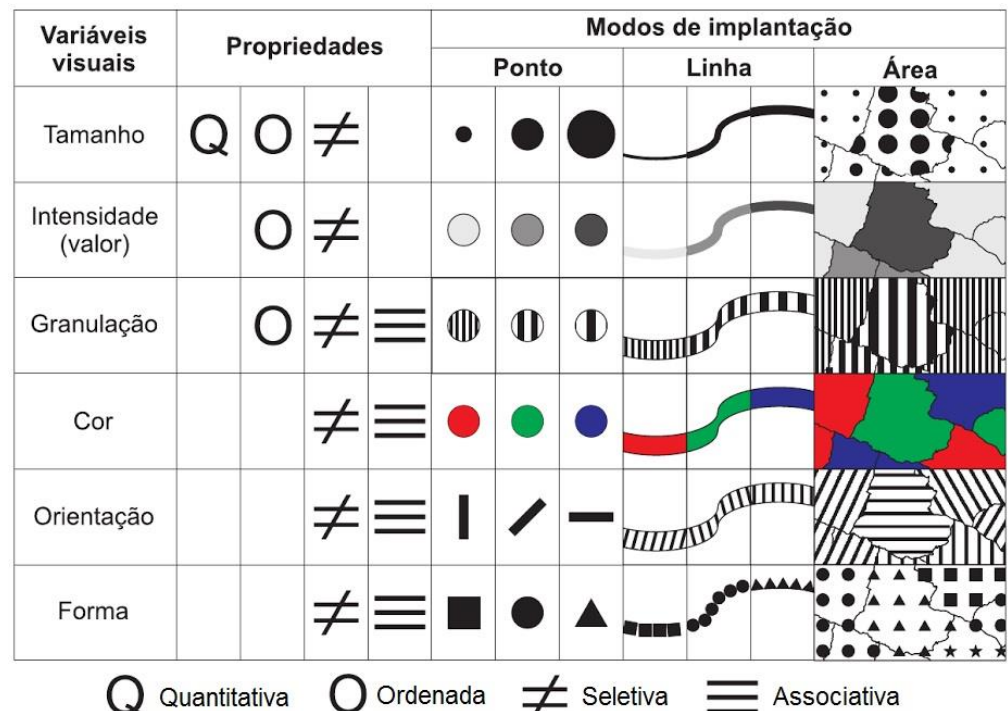

Fonte: adaptado de Cardoso (1984).

Na segunda, foram analisadas as variáveis visuais utilizadas na representação gráfica de cada um dos cinco atributos do relevo. Considerou-se a proposta de Bertin (1967), ilustrada pela Figura 2, com as variáveis 
visuais: tamanho, intensidade (valor), granulação (textura), cor, orientação e forma, implementadas em pontos, linhas e polígonos. Por fim, os resultados da análise foram tabelados e quantificados.

\section{RESULTADOS E DISCUSSÕES}

A etapa de avaliação dos produtos cartográficos sob a perspectiva geomorfológica e temática contemplou a análise de 57 mapas geomorfológicos, sendo 23 de mapeamentos nacionais, 6 mapeamentos de estados do Brasil e 28 mapeamentos de regiões, com recortes específicos, de diversos locais do mundo.

Os resultados qualitativos tabulados são apresentados pelas Tabelas 1 (mapas nacionais), 2 (mapas estaduais) e 3 (mapas de regiões), que indicam: localidade, escala, autoria, ênfase, variáveis visuais utilizadas para a representação dos aspectos geomorfológicos (morfometria, morfografia, morfogênese, morfodinâmica, morfocronologia) e informações adicionais contidas nos mapas. Já as quantificações dos resultados, considerando o conjunto total de mapas interpretados, são dispostas pelas Figuras 3, 4, 5, 6, 7, 8 e 9.

Destaca-se, inicialmente, que apenas 32 dos 57 mapas analisados (56\% do total) representaram todos os elementos que um mapa geomorfológico deve conter, mesmo considerando as indicações implícitas. Dos mapas estaduais, apenas São Paulo (ROSS; MOROZ, 1997) contemplou todos os aspectos.

Referente à ênfase dos mapeamentos (Figura 3), constatou-se que 26\% dos mapas nacionais priorizaram a visualização da morfogênese e morfografia (de modo concomitante), ao passo que $22 \%$ dos mapas de regiões enfatizaram a morfografia e outros $22 \%$ a morfogênese. Ao somar a ocorrência de cada aspecto geomorfológico, verificou-se que a morfografia e morfogênese apareceram, cada uma, enfatizadas por $73,9 \%$ dos mapas nacionais, enquanto nos mapas de regiões a ocorrência foi de $50 \%$ para a morfogênese, 42,9\% para a morfografia e 39,3\% para a morfodinâmica. Os mapas estaduais, para ambos os casos, resultaram em $100 \%$ com ênfase morfográfica.

No conjunto total de mapas, a morfografia foi enfatizada por $61,4 \%$ e a morfogênese por $52,6 \%$, o que reforça a importância dedicada a esses aspectos no âmbito geral. Por outro lado, a morfometria apareceu como principal aspecto em apenas $3,5 \%$ e a morfocronologia em $1,7 \%$ da totalidade de mapas.

Esses resultados demonstram, num primeiro momento, que há correlação entre o nível de abrangência dos mapeamentos e os objetivos priorizados para a representação geomorfológica. Nos produtos de âmbito nacional, os sistemas de mapeamento majoritariamente se apoiam em unidades morfográficas ou morfogenéticas representadas por grandes polígonos que buscam evidenciar determinado nível de homogeneidade. Em mapas de pequena escala, como China 1:1.000.000 (CHENG et al., 2011) e República Tcheca 1:500.000 (DEMEK et al., 2009), a adoção dessas grandes unidades pode ser justificada pelo caráter generalista da representação, o que dificulta ilustrar as mensurações, idades ou processos atuantes como o aspecto de destaque. Entretanto, mesmo em mapeamentos de grande escala, como o alemão 1:25.000 (LESER; STÄBLEIN, 1975), ou de média escala, como o espanhol (GARCÍA; CERDÁN, 2006) e italiano (SGN, 1994) 1:50.000, há a preocupação em realçar as formas e a gênese do relevo de modo compreensível e aplicável a todo o país. Em outras palavras, ainda que o produto seja de detalhe, a vinculação com o contexto geral, mais amplo, sistematizado, influencia na escolha dos elementos a serem frisados.

Os mapas de regiões, em contrapartida, demonstraram maior flexibilidade para elencar o aspecto geomorfológico salientado. A adoção de recortes específicos e com escalas de detalhe favoreceram a indicação da morfodinâmica, já que mais de 1/3 dos mapas priorizaram esse aspecto. Todos os mapas analisados com escala maior que 1:15.000, por exemplo, possuem a morfodinâmica como elemento de destaque. Apesar de ser uma tendência, não é um fator excludente, já que dois mapas de média escala (1:50.000), do Chile (MURO et al., 2015) e Espanha (CABALLERO et al., 2016), também ressaltam processos geomorfológicos atuantes. Para a morfometria e morfocronologia, com apenas 3,6\% para cada, a flexibilidade oferecida pelos mapas de regiões não alterou a tendência apresentada em relação ao conjunto total de mapas. Especialmente para os mapas de grande escala, chama a atenção o fato de pouco aproveitarem informações morfométricas. A litologia, mesmo não sendo um aspecto elementar do mapa geomorfológico, teve o dobro de ocorrência enfatizada: $7,1 \%$. 
Tabela 1 - Análise geomorfológica e temática de mapas geomorfológicos nacionais.

IG: implantação gráfica; VV: variável visual.

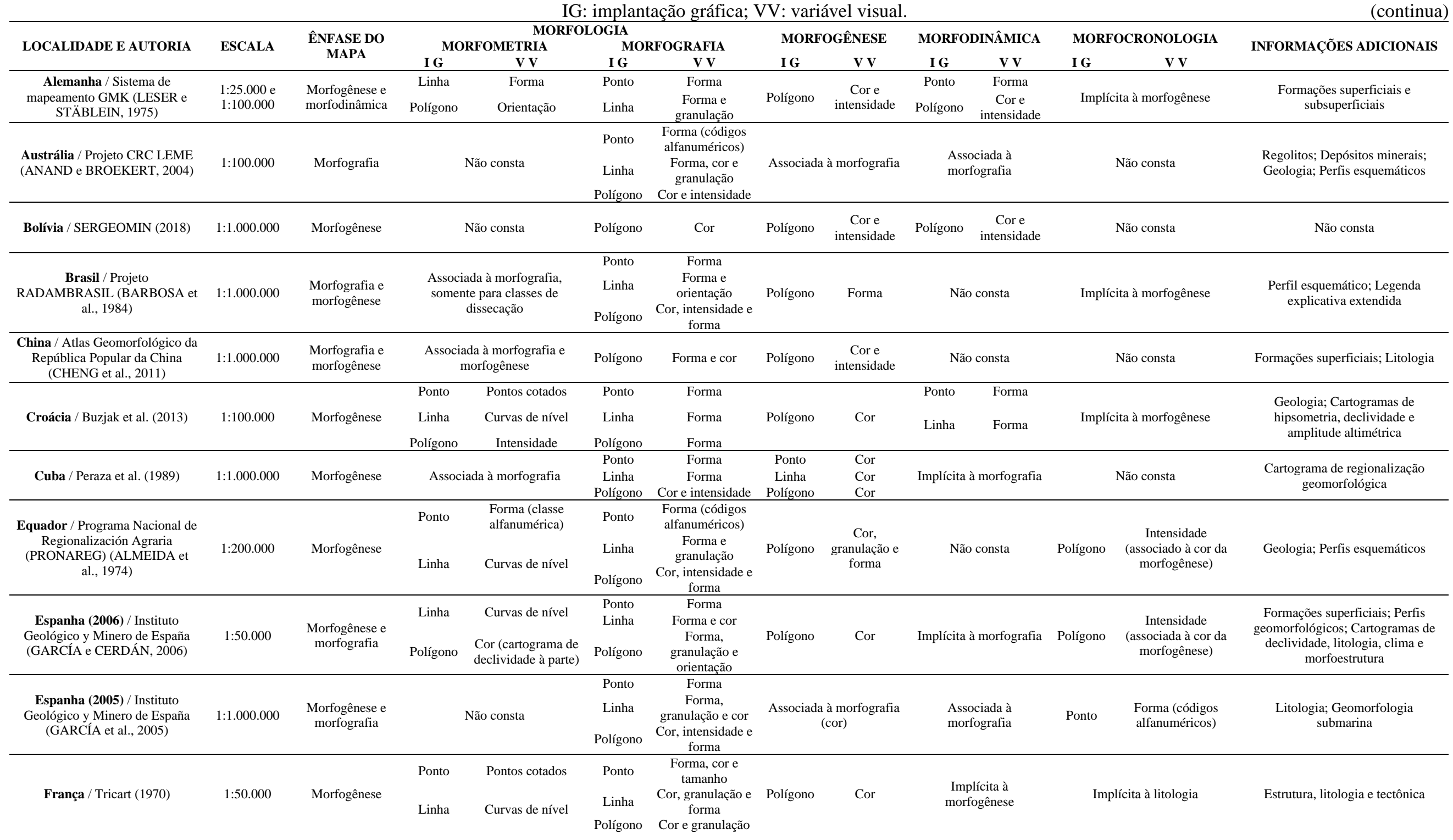




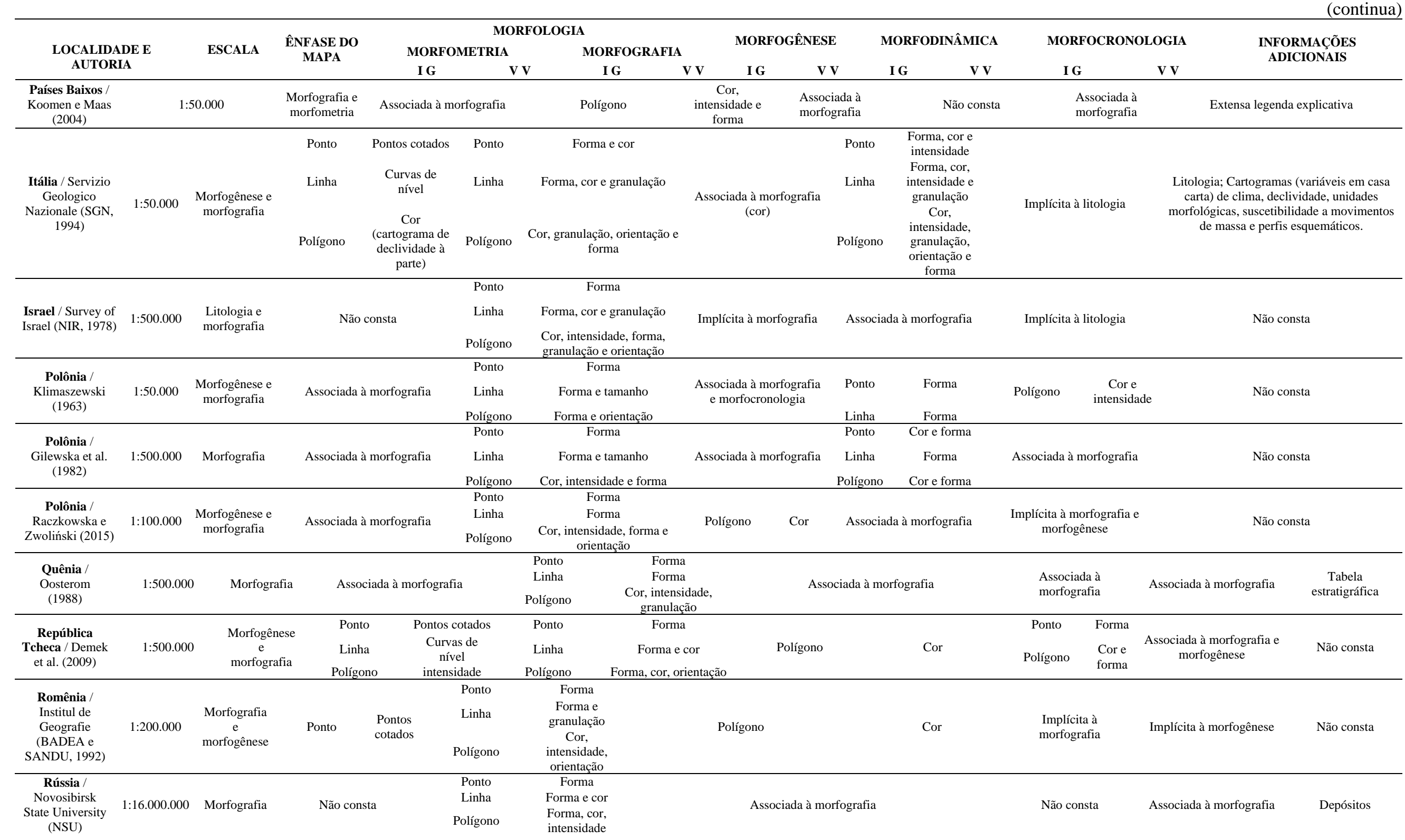


(conclusão)

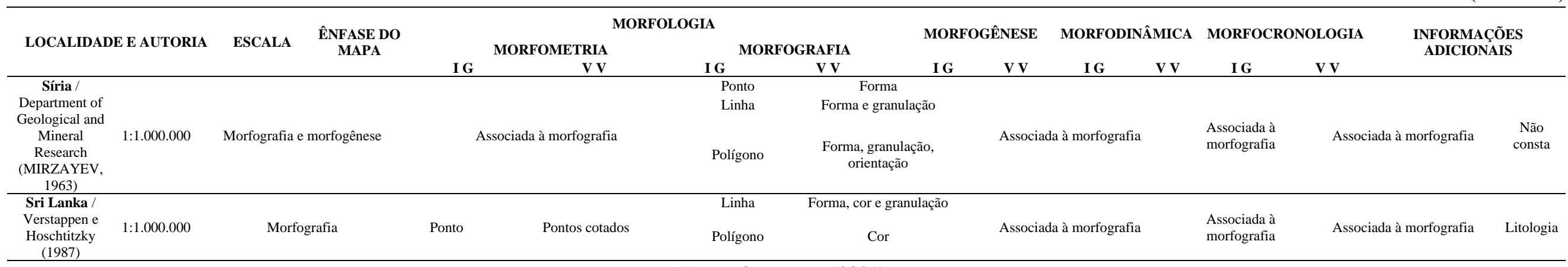

Fonte: Os autores (2021).

Tabela 2 - Análise geomorfológica e temática de mapas geomorfológicos estaduais.

IG: implantação gráfica; VV: variável visual.

\begin{tabular}{|c|c|c|c|c|c|c|c|c|c|c|c|}
\hline \multirow{3}{*}{ LOCALIDADE E AUTORIA } & \multirow{3}{*}{ ESCALA } & \multirow{3}{*}{$\begin{array}{l}\text { ÊNFASE DO } \\
\text { MAPA }\end{array}$} & \multicolumn{4}{|c|}{ MORFOLOGIA } & \multirow{2}{*}{ MORFOGÊNESE } & \multirow{2}{*}{\multicolumn{2}{|c|}{ MORFODINÂMICA }} & \multirow{2}{*}{ MORFOCRONOLOGIA } & \multirow{3}{*}{$\begin{array}{l}\text { INFORMAÇÕES } \\
\text { ADICIONAIS }\end{array}$} \\
\hline & & & \multicolumn{2}{|c|}{ MORFOMETRIA } & \multicolumn{2}{|c|}{ MORFOGRAFIA } & & & & & \\
\hline & & & I G & $\mathbf{V} \mathbf{V}$ & I G & $\mathbf{v} \mathbf{V}$ & $\mathbf{V} \mathbf{V}$ & I G & $\mathbf{v} \mathbf{v}$ & $\mathbf{v} \mathbf{v}$ & \\
\hline $\begin{array}{l}\text { Espírito Santo / IJSN/UFES } \\
\text { (COELHO et al., 2012) }\end{array}$ & 1:250.000 & Morfografia & & Não consta & Polígono & Cor, intensidade e forma & $\begin{array}{l}\text { Implícita à } \\
\text { morfografia }\end{array}$ & Não cc & & Implícita à morfografia & Relatório descritivo \\
\hline $\begin{array}{l}\text { Paraná / UFPR/Mineropar } \\
\text { (SANTOS et al., 2006; OKA- } \\
\text { FIORI et al., 2006) }\end{array}$ & $1: 250.000$ & Morfografia & \multicolumn{2}{|c|}{$\begin{array}{l}\text { Associada à morfografia (em tabela } \\
\text { descritiva, à parte) }\end{array}$} & Polígono & Cor e intensidade & $\begin{array}{l}\text { Implícita à } \\
\text { morfografia }\end{array}$ & \multicolumn{2}{|c|}{ Não consta } & Implícita à morfografia & Atlas descritivo \\
\hline $\begin{array}{l}\text { Rio de Janeiro / Projeto Rio de } \\
\text { Janeiro (CPRM, 2000) }\end{array}$ & $1: 250.000$ & Morfografia & \multicolumn{2}{|c|}{ Implícita à morfografia } & Polígono & Cor e intensidade & $\begin{array}{l}\text { Implícita à } \\
\text { morfografia }\end{array}$ & \multicolumn{2}{|c|}{ Não consta } & Não consta & Não consta \\
\hline $\begin{array}{l}\text { Rio Grande do Norte / Diniz et } \\
\text { al. (2017) }\end{array}$ & $1: 250.000$ & Morfografia & \multicolumn{2}{|c|}{$\begin{array}{l}\text { Associada à morfografia (em tabela } \\
\text { descritiva, à parte) }\end{array}$} & Polígono & Cor e intensidade & $\begin{array}{l}\text { Implícita à } \\
\text { morfografia }\end{array}$ & \multicolumn{2}{|c|}{ Não consta } & Implícita à morfografia & Não consta \\
\hline \multirow[t]{2}{*}{ São Paulo / Ross e Moroz (1997) } & \multirow[t]{2}{*}{$1: 500.000$} & \multirow[t]{2}{*}{ Morfografia } & \multirow[t]{2}{*}{ Polígono } & \multirow[t]{2}{*}{ Associada à morfografia } & Ponto & $\begin{array}{l}\text { Forma (códigos } \\
\text { alfanuméricos) }\end{array}$ & \multirow[t]{2}{*}{$\begin{array}{l}\text { Associada à } \\
\text { morfografia }\end{array}$} & \multirow[t]{2}{*}{ Polígono } & \multirow[t]{2}{*}{ Forma } & \multirow[t]{2}{*}{ Implícita à morfografia } & \multirow[t]{2}{*}{$\begin{array}{l}\text { Solos; Litologia; Fragilidade } \\
\text { potencial }\end{array}$} \\
\hline & & & & & Polígono & Cor e forma & & & & & \\
\hline
\end{tabular}

Fonte: Os autores (2021). 
Tabela 3 - Análise geomorfológica e temática de mapas geomorfológicos de regiões.

IG: implantação gráfica; VV: variável visual.

(continua)

\begin{tabular}{|c|c|c|c|c|c|c|c|c|c|c|c|c|c|}
\hline \multirow{3}{*}{ LOCALIDADE E AUTORIA } & \multirow{3}{*}{ ESCALA } & \multirow{3}{*}{$\begin{array}{l}\text { ÊNFASE DO } \\
\text { MAPA }\end{array}$} & \multicolumn{4}{|c|}{ MORFOLOGIA } & \multirow{2}{*}{\multicolumn{2}{|c|}{ MORFOGÊNESE }} & \multirow{2}{*}{\multicolumn{2}{|c|}{ MORFODINÂMICA }} & \multirow{2}{*}{\multicolumn{2}{|c|}{ MORFOCRONOLOGIA }} & \multirow{3}{*}{$\begin{array}{l}\text { INFORMAÇÕES } \\
\text { ADICIONAIS }\end{array}$} \\
\hline & & & \multicolumn{2}{|c|}{ MORFOMETRIA } & \multicolumn{2}{|c|}{ MORFOGRAFIA } & & & & & & & \\
\hline & & & I G & $\mathbf{v} \mathbf{v}$ & I G & $\mathbf{V} \mathbf{V}$ & I G & $\mathbf{v} \mathbf{v}$ & IG & $\mathbf{v} \mathbf{v}$ & I G & $\mathbf{V} \mathbf{v}$ & \\
\hline \multirow{2}{*}{$\begin{array}{l}\text { Argentina (Mendoza) / } \\
\text { Abraham (1996) }\end{array}$} & \multirow[b]{2}{*}{$1: 100.000$} & \multirow[b]{2}{*}{ Morfografia } & \multirow{2}{*}{\multicolumn{2}{|c|}{ Não consta }} & Ponto & Forma & \multirow{2}{*}{\multicolumn{2}{|c|}{ Associada à morfografia }} & Ponto & Forma e cor & \multirow{2}{*}{\multicolumn{2}{|c|}{ Associada à morfografia }} & \\
\hline & & & & & Polígono & $\begin{array}{c}\text { Forma e } \\
\text { granulação }\end{array}$ & & & Linha & Forma & & & Não consta \\
\hline \multirow{2}{*}{$\begin{array}{c}\text { Argentina (Quebrada de } \\
\text { Purmamarca, Jujuy) / May } \\
\text { (2008) }\end{array}$} & \multirow[t]{2}{*}{ 1:10.000 } & \multirow{2}{*}{$\begin{array}{l}\text { Morfogênese e } \\
\text { morfodinâmica }\end{array}$} & & & & & \multirow[t]{2}{*}{ Polígono } & \multirow[t]{2}{*}{ Cor e intensidade } & \multirow[t]{2}{*}{ Ponto } & \multirow[t]{2}{*}{ Forma } & \multirow{2}{*}{\multicolumn{2}{|c|}{ Implícita à morfogênese }} & Não consta \\
\hline & & & Linha & Curvas de nível & Polígono & Forma & & & & & & & \\
\hline $\begin{array}{l}\text { Áustria (Glaciar Pasterze) / } \\
\text { Geilhausen e Schrott (2012) }\end{array}$ & $1: 12.500$ & Morfodinâmica & Linha & $\begin{array}{l}\text { Curvas de nível e } \\
\text { forma }\end{array}$ & Linha & Forma & Polígono & Cor & Ponto & Forma & Imp & Í́cita à geologia & $\begin{array}{l}\text { Cartograma de geologia, } \\
\text { declividade e vegetacão }\end{array}$ \\
\hline & & & Linha & Curvas de nível & Ponto & Forma & & & & & & & \\
\hline $\begin{array}{l}\text { Brasil (Garuva, Santa } \\
\text { Catarina) / Oliveira e Vieira }\end{array}$ & $1: 65.000$ & Morfografia & Polígono & Cor (cartograma de & & $\begin{array}{l}\text { Forma, cor e } \\
\text { granulação }\end{array}$ & Polígono & $\begin{array}{c}\text { Cor (associada à } \\
\text { morfografia) }\end{array}$ & Ponto & Forma & & Não consta & $\begin{array}{c}\text { Cartograma de geologia e } \\
\text { declividade }\end{array}$ \\
\hline & & & & declividade à parte) & Polígono & $\begin{array}{c}\text { Cor e } \\
\text { intensidade } \\
\end{array}$ & & & & & & & \\
\hline Brasil (São Pedro, São Paulo) / & 1.50 .000 & Morfografia & Ponto & Pontos cotados & & & Associa & da à morfografia & Associad & à morfografia & Ponto & Forma (códigos & Litologia \\
\hline Queiroz Neto e Journaux (1977) & & & & & Linha & $\begin{array}{c}\text { Forma e } \\
\text { granulação }\end{array}$ & & & & & & alfanuméricos) & \\
\hline Chile (Península Juan Mazía, & 150000 & Morfogênese e & Ponto & Pontos cotados & Linha & Cor e forma & & Cort & Ponto & Forma & & & \\
\hline $\begin{array}{l}\text { Terra do Fogo) / Muro et al. } \\
\text { (2015) }\end{array}$ & $1: 50.000$ & morfodinâmica & Linha & & Polígono & Cor e granulação & Polígono & Cor & Linha & $\begin{array}{l}\text { Forma, cor e } \\
\text { granulacão }\end{array}$ & Implíc & ita à morfogênese & Depósitos; Dinâmica costeira \\
\hline & & & Ponto & $\begin{array}{c}\text { Forma e intensidade } \\
\text { numérica }\end{array}$ & Ponto & Forma & & & & & & & \\
\hline $\begin{array}{l}\text { Espanha (Sierra Gorda) / } \\
\text { Caballero et al. (2016) }\end{array}$ & $1: 33.000$ & $\begin{array}{l}\text { Morfografia e } \\
\text { morfogênese }\end{array}$ & & & Linha & Forma e cor & Polígono & Cor e orientação & Implícita & à morfografia & & Não consta & Litologia \\
\hline & & & Linha & Curvas de nível & Polígono & $\begin{array}{l}\text { Cor, intensidade } \\
\text { e granulação }\end{array}$ & & & & & & & \\
\hline $\begin{array}{c}\text { Espanha (Burgos) / Calvo e } \\
\text { González (2015) }\end{array}$ & $1: 25.000$ & $\begin{array}{l}\text { Morfogênese e } \\
\text { morfocronologia }\end{array}$ & $\begin{array}{l}\text { Ponto } \\
\text { Linha }\end{array}$ & $\begin{array}{l}\text { Pontos cotados } \\
\text { Curvas de nível }\end{array}$ & $\begin{array}{c}\text { Linha } \\
\text { Polígono }\end{array}$ & $\begin{array}{l}\text { Cor e forma } \\
\text { Cor e forma }\end{array}$ & Polígono & Cor e forma & $\begin{array}{r}\text { Implícita } \\
\text { mol }\end{array}$ & $\begin{array}{l}\text { morfografia e } \\
\text { fogênese }\end{array}$ & Polígono & $\begin{array}{l}\text { Cor, intensidade e } \\
\text { forma }\end{array}$ & $\begin{array}{l}\text { Geologia; Perfis esquemáticos; } \\
\text { Representação em 3D }\end{array}$ \\
\hline & & & & & Ponto & Forma & & & Ponto & Forma e cor & & & \\
\hline $\begin{array}{l}\text { Espanha (Alta Ribagorza) / } \\
\text { Cía e Andrés (2008) }\end{array}$ & $1: 50.000$ & $\begin{array}{l}\text { Litologia e } \\
\text { morfodinâmica }\end{array}$ & Linha & Curvas de nível & Linha & Forma e cor & Associad & a à morfografia e & Linha & Forma & Imp & lícita à litologia & Litologia; Fotografias aéreas; \\
\hline & & & & & Polígono & Cor e forma & & & Polígono & Forma e cor & & & \\
\hline & & & Ponto & Pontos cotados & Ponto & Forma e cor & & & Linha & Cor e forma & & & \\
\hline Aradam, Tigray) / Coltorti et & $1: 25.000$ & Morfocronologia & & & & Eormo cor & Implícita & à morfocronologia & & & Polígono & Cor e forma & Perfil esquemático \\
\hline al. ( & & & Linha & Curvas de nível & Polígono & $\begin{array}{c}\text { Forma e cor } \\
\text { Orientação }\end{array}$ & & & Polígono & Cor e forma & & & \\
\hline $\begin{array}{l}\text { Grécia (Delta do rio Pinios) / } \\
\text { Karymbalis et al. (2016) }\end{array}$ & $1: 15.000$ & $\begin{array}{l}\text { Morfografia e } \\
\text { morfodinâmica }\end{array}$ & Linha & Curvas de nível & $\begin{array}{l}\text { Linha } \\
\text { Polígono }\end{array}$ & $\begin{array}{l}\text { Forma e cor } \\
\text { Forma e cor }\end{array}$ & Associa & da à morfografia & $\begin{array}{l}\text { Ponto } \\
\text { Linha }\end{array}$ & $\begin{array}{l}\text { Cor e forma } \\
\text { Cor e forma }\end{array}$ & Imp & lícita à geologia & $\begin{array}{l}\text { Dinâmica costeira, litologia e } \\
\text { tabela com dados descritivos }\end{array}$ \\
\hline
\end{tabular}


(continua)

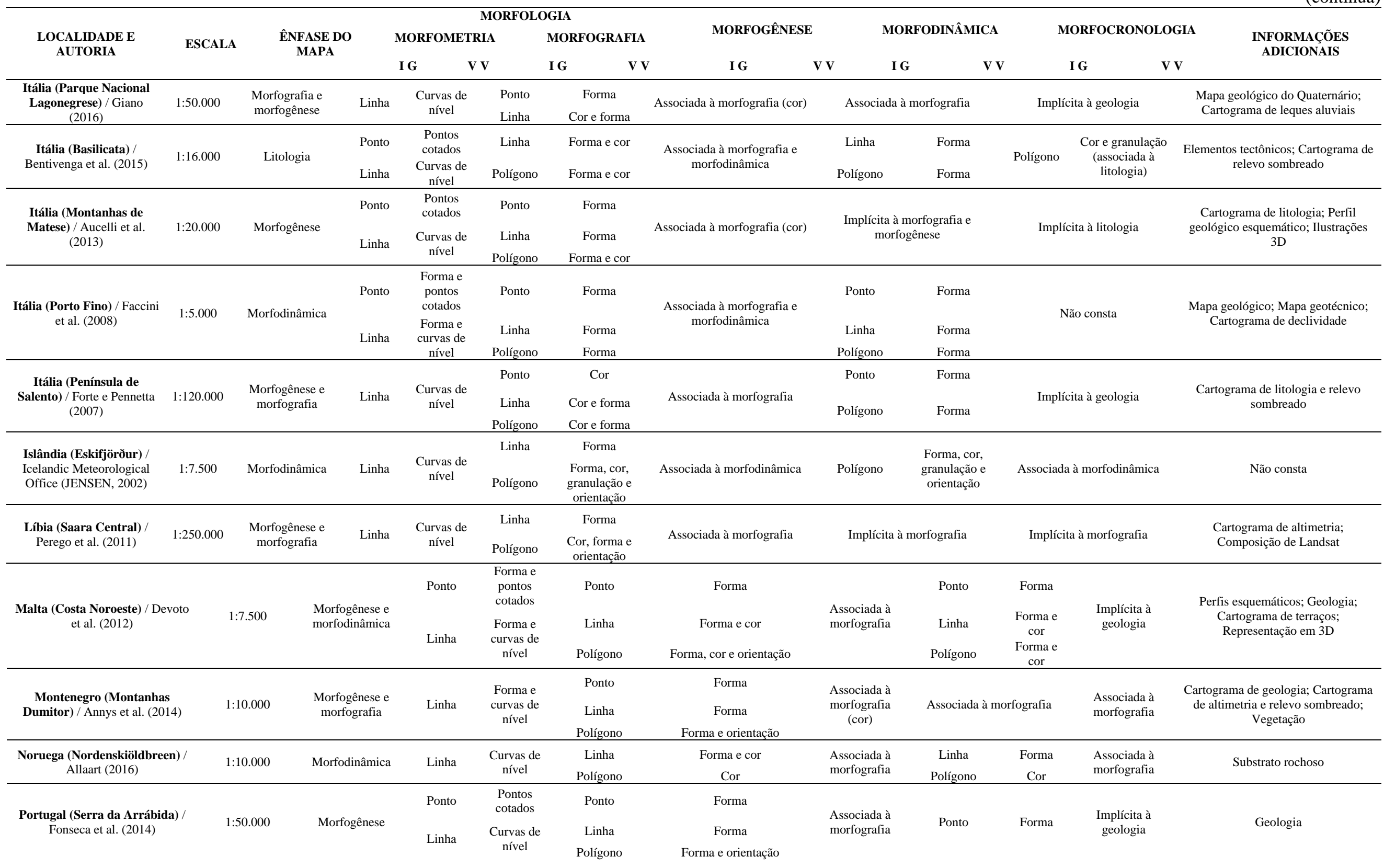




\begin{tabular}{|c|c|c|c|c|c|c|c|c|c|c|c|c|}
\hline \multirow{3}{*}{$\begin{array}{c}\text { LOCALIDADE E } \\
\text { AUTORIA }\end{array}$} & \multirow{3}{*}{$\begin{array}{l}\text { ÊNFASE DO } \\
\text { MAPA }\end{array}$} & \multicolumn{4}{|c|}{ MORFOLOGIA } & \multirow{2}{*}{\multicolumn{2}{|c|}{ MORFOGÊNESE }} & \multirow{2}{*}{\multicolumn{2}{|c|}{ MORFODINÂMICA }} & \multirow{2}{*}{\multicolumn{2}{|c|}{ MORFOCRONOLOGIA }} & \multirow{3}{*}{$\begin{array}{l}\text { INFORMAÇÕES } \\
\text { ADICIONAIS }\end{array}$} \\
\hline & & \multicolumn{2}{|c|}{ MORFOMETRIA } & \multicolumn{2}{|c|}{ MORFOGRAFIA } & & & & & & & \\
\hline & & I G & $\mathbf{v ~ V ~}$ & IG & $\mathbf{v} \mathbf{v}$ & I G & $\mathbf{v} \mathbf{v}$ & I G & v v & & I G & \\
\hline \multirow{3}{*}{$\begin{array}{c}\text { Portugal (Serra de Montejunto) / Fonseca } \\
\text { (2011) }\end{array}$} & \multirow{3}{*}{$1: 25.000$} & \multirow{3}{*}{ Morfografia } & Ponto & Pontos cotados & Ponto & Forma & \multirow{3}{*}{$\begin{array}{l}\text { Associad } \\
\text { morfograt }\end{array}$} & & Ponto & $\begin{array}{c}\text { Forma e } \\
\text { intensidade }\end{array}$ & \multirow{3}{*}{ Implícita à geologia } & \multirow{3}{*}{ Geologia } \\
\hline & & & \multirow{2}{*}{ Linha } & \multirow{2}{*}{ Curvas de nível } & Linha & Forma & & & Linha & $\begin{array}{c}\text { Forma e } \\
\text { intensidade }\end{array}$ & & \\
\hline & & & & & Polígono & Forma & & & Polígono & $\begin{array}{c}\text { Forma e } \\
\text { intensidade }\end{array}$ & & \\
\hline \multirow[b]{2}{*}{$\begin{array}{l}\text { Principado de Liechtenstein (Malbun) / } \\
\text { Seijmonsbergen e Graaff (2006) }\end{array}$} & \multirow[b]{2}{*}{$1: 3.000$} & \multirow[b]{2}{*}{$\begin{array}{l}\text { Morfogênese e } \\
\text { morfografia }\end{array}$} & \multirow[b]{2}{*}{ Linha } & \multirow[b]{2}{*}{$\begin{array}{l}\text { Curvas de nível } \\
\text { (sem cota) }\end{array}$} & Ponto & Forma & \multirow[b]{2}{*}{ Polígono } & \multirow[b]{2}{*}{ Cor } & Ponto & Forma & \multirow[b]{2}{*}{ Não consta } & \multirow[b]{2}{*}{$\begin{array}{l}\text { Processos geomorfológicos e } \\
\text { zonas de perigo }\end{array}$} \\
\hline & & & & & Linha & Forma & & & Poligono & Forma & & \\
\hline Romênia (Prahova) / Grecu (2009) & $1: 25.000$ & Morfografia & Ponto & Pontos cotados & $\begin{array}{c}\text { Ponto } \\
\text { Linha } \\
\text { Polígono }\end{array}$ & $\begin{array}{l}\text { Forma } \\
\text { Forma } \\
\text { Forma }\end{array}$ & \multicolumn{2}{|c|}{$\begin{array}{l}\text { Associada à } \\
\text { morfografia }\end{array}$} & \multicolumn{2}{|c|}{ Associada à morfografia } & Não consta & Relevo sombreado \\
\hline $\begin{array}{l}\text { Rússia (Bacia de Pechora) / Nikolskaya et al. } \\
\text { (2002) }\end{array}$ & $1: 1.000 .000$ & Morfogênese & Linha & $\begin{array}{l}\text { Curvas de nível } \\
\text { (sem cota) }\end{array}$ & Polígono & Cor & Polígono & Cor & \multicolumn{2}{|c|}{ Não consta } & Polígono & Não consta \\
\hline $\begin{array}{l}\text { Suíça (Vales Hérens, Alpes) / Otto e Dikau } \\
\text { (1994) }\end{array}$ & $1: 25.000$ & $\begin{array}{l}\text { Morfogênese e } \\
\text { morfodinâmica }\end{array}$ & Linha & $\begin{array}{l}\text { Forma, cor e } \\
\text { curvas de nível }\end{array}$ & $\begin{array}{c}\text { Ponto } \\
\text { Linha } \\
\text { Polígono } \\
\end{array}$ & $\begin{array}{c}\text { Forma } \\
\text { Forma e cor } \\
\text { Forma e cor }\end{array}$ & Polígono & Cor & $\begin{array}{c}\text { Ponto } \\
\text { Polígono }\end{array}$ & $\begin{array}{c}\text { Forma } \\
\text { Cor }\end{array}$ & Não consta & Não consta \\
\hline $\begin{array}{l}\text { Suíça (Vale Turtmann, Valais) / Lambiel et } \\
\text { al. (2016) }\end{array}$ & $1: 25.000$ & $\begin{array}{l}\text { Morfogênese e } \\
\text { morfodinâmica }\end{array}$ & $\begin{array}{c}\text { Linha } \\
\text { Polígono }\end{array}$ & $\begin{array}{c}\text { Forma } \\
\text { Orientação }\end{array}$ & $\begin{array}{l}\text { Ponto } \\
\text { Linha } \\
\end{array}$ & $\begin{array}{c}\text { Forma } \\
\text { Forma e } \\
\text { granulação }\end{array}$ & Polígono & Cor & $\begin{array}{c}\text { Ponto } \\
\text { Polígono } \\
\end{array}$ & $\begin{array}{c}\text { Forma } \\
\text { Cor } \\
\end{array}$ & Implícita à morfogênese & $\begin{array}{l}\text { Formações superficiais; } \\
\text { Cartograma geológico }\end{array}$ \\
\hline
\end{tabular}

Fonte: Os autores (2021). 
Quanto aos mapas estaduais, o principal ponto de destaque foi a padronização verificada. Todos os mapeamentos expuseram como destaque a morfografia, com grandes unidades homogêneas e cuja interpretação de outros aspectos aparece de modo implícito ou associado às próprias unidades - diferentemente do mapa de âmbito nacional, realizado pelo Projeto RADAMBRASIL (BARBOSA et al., 1984) na escala 1:1.000.000, que mesmo em escala menor representa um número maior de objetos e aspectos geomorfológicos.

As semelhanças podem ser justificadas pelas metodologias comumente utilizadas para a realização dos mapeamentos no Brasil, que priorizam a identificação e caracterização de unidades morfográficas homogêneas. Os mapas do estado do Paraná (SANTOS et al., 2006), de São Paulo (ROSS; MOROZ, 1997) e do Rio Grande do Norte (DINIZ et al., 2017) seguem a proposta hierárquica taxonômica de Ross (1992), embasada pelos conceitos de morfoestrutura e morfoescultura da escola russa (MESCERJAKOV, 1968; GERASSIMOV; MESCHERIKOV, 1968). O mapa do Espírito Santo (COELHO et al., 2012) segue proposição derivada do próprio Projeto RADAMBRASIL (IBGE, 2009), com os modelados de agradação, dissecação e aplanamento. Os mapeamentos de Goiás (LATRUBESSE; CARVALHO, 2006) e Rio de Janeiro (CPRM, 2000), mesmo com informações específicas apresentam elementos de ambas as propostas

Assim, para essa categoria, denota-se a ênfase da representação por níveis hierárquicos (ou taxonômicos, em unidades ou modelados). Entretanto, constatou-se uma significativa diferença em relação aos mapas nacionais e de regiões analisados que também enfatizam a morfografia. Há, nos mapas estaduais, uma dependência em relação às unidades morfográficas, enquanto os outros aspectos geomorfológicos são por vezes suprimidos ou secundarizados, limitando-se a interpretações implícitas ou associadas aos polígonos ou necessidade de consulta a extensos relatórios descritivos adicionais. Em mapeamentos como o da Polônia 1:500.000 (GILEWSKA et al., 1982) ou 1:100.000 (RACZKOWSKA; ZWOLIŃSKI, 2015), por exemplo, prioriza-se a morfografia sem que haja omissão de outras dimensões de representação geomorfológica.

Os resultados referentes à análise da representação da morfometria indicaram que os pontos cotados e as curvas de nível são as principais variáveis utilizadas, aparecendo em $28 \%$ e $49,1 \%$ do total de mapas, respectivamente (Figura 4). A predominante adoção de pontos (35\%) e linhas $(57,8 \%)$ como feições geométricas, bem como a baixa representação morfométrica por polígonos (14\%), portanto, é justificada pela facilidade de inclusão de dados planialtimétricos elementares que constam em cartas topográficas utilizadas como base para os mapeamentos.

Dos 57 mapas interpretados, 8 (14\%) não representaram quaisquer elementos morfométricos, enquanto $12(21 \%)$ tiveram a representação associada à morfografia, principalmente vinculada aos polígonos de unidades homogêneas com a indicação alfanumérica de padrões mensuráveis do relevo. Essa característica foi evidenciada apenas para mapas com escala menor que 1:50.000, sendo uma solução para indicações quantitativas mesmo em escalas médias e pequenas.

Ao categorizar os dados da avaliação morfométrica, constatou-se que os mapas nacionais utilizam mais polígonos $(21,7 \%)$ e menos linhas $(30,4 \%)$ do que o conjunto total, enquanto os pontos se mantêm proporcionais $(30,4 \%)$. Dos mapas de regiões destaca-se a majoritária adoção de feições lineares, em 85,7\% dos produtos, e também maior diversidade na escolha das variáveis visuais. Os mapas estaduais sequer incluem pontos cotados ou curvas de nível aos produtos cartográficos.

De todos os mapas, destaca-se a representação morfométrica do mapeamento alemão (LESER e STÄBLEIN, 1975), tanto na escala 1:25.000 quanto 1:100.000, com linhas em diversos formatos e polígonos orientados que conferem ampla caracterização das dimensões do relevo. Por outro lado, a leitura do mapa é dificultada em função do excesso de informações cartografadas. Outro mapeamento de destaque, nesse aspecto, é o holandês 1:50.000 (KOOMEN e MAAS, 2004), cujo sistema de mapeamento teve como base unidades definidas por intervalos morfométricos (declividade e amplitude altimétrica) associada à atribuição morfográfica qualitativa.

Para a morfografia, denotada pela análise como o aspecto de maior destaque dos mapas geomorfológicos, já que $100 \%$ dos mapas conferidos indicaram a aparência do relevo, destaca-se a expressiva utilização de polígonos, com 96,4\%, seguida de 80,7\% para linhas e 66,6\% para pontos (Figura 5). Além disso, o emprego de polígonos associado à diferenciação por cores corrobora, numa perspectiva temática, a ênfase dos mapeamentos dada à morfografia, conforme discutido anteriormente. Isso por que, visualmente, a 
representação de área com cores é o elemento em evidência do mapa.

Figura 3 - Ênfase dos mapeamentos geomorfológicos analisados.
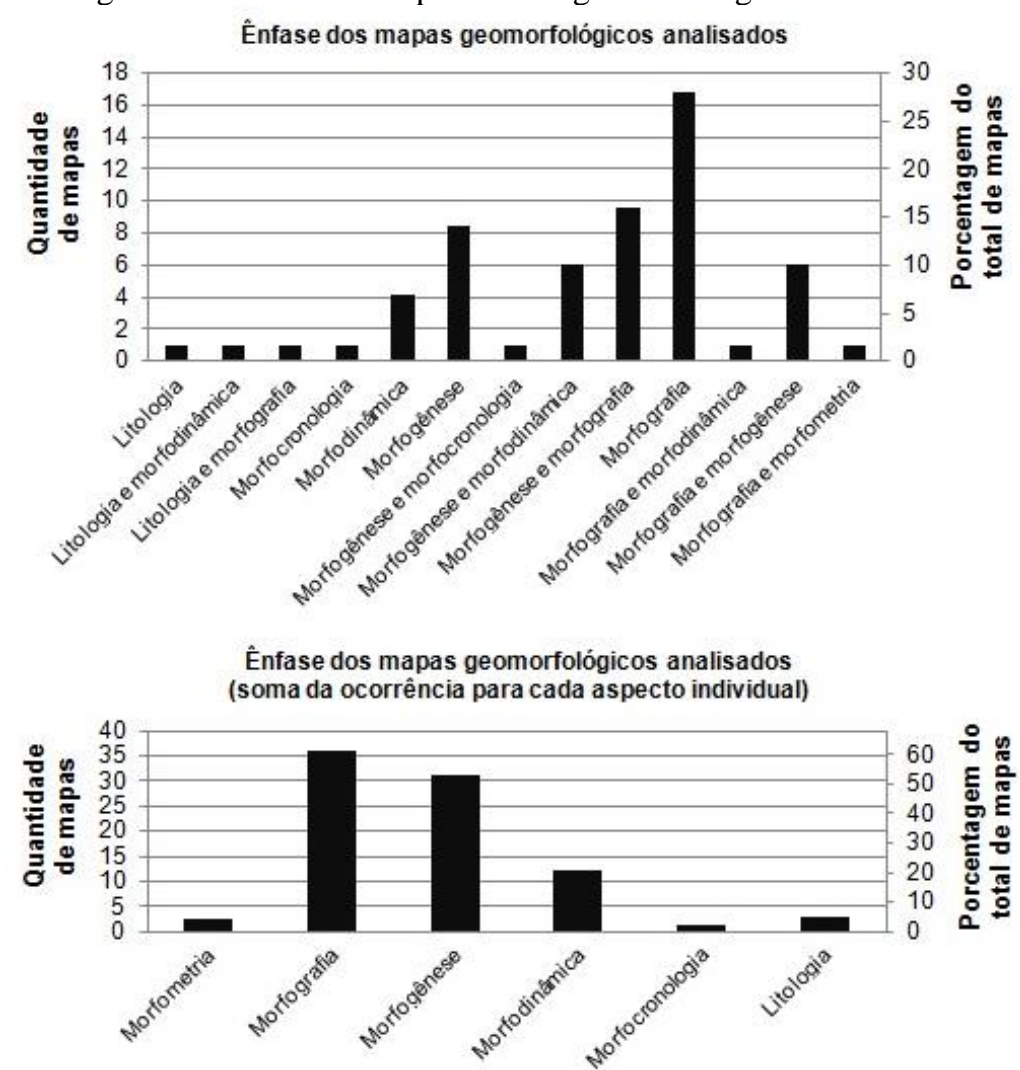

Fonte: Os autores (2021).

Além da cor, a variável visual forma também foi muito aplicada: consta em 54,3\% dos mapas implantada na forma de pontos, $80,7 \%$ em linhas e $64,9 \%$ em polígonos. Principalmente para mapas em que as cores foram atribuídas à morfogênese, a solução cartográfica para representação da morfografia se deu a partir da inclusão de símbolos (formas), como nos mapas da Croácia (BUZJAK et al., 2013), do Equador (ALMEIDA et al., 1979), da Itália (SGN, 1994), do Monte Durmitor em Montenegro (ANNYS et al., 2014) ou Vale Turtmann na Suíça (LAMBIEL et al., 2016). Também há os casos em que a variável forma foi implantada para subdividir classes morfográficas indicadas por cores, como no mapeamento brasileiro (BARBOSA et al., 1984) e do estado de São Paulo (ROSS; MOROZ, 1997).

$\mathrm{Na}$ análise por nível de abrangência, observou-se a mesma tendência apresentada em relação à morfometria: i) ampla utilização de feições geométricas e maior conformidade de representação entre pontos (82,6\%), linhas (87\%) e polígonos (95,7\%) nos mapas nacionais; ii) destacada inserção de linhas (92,9\%) e polígonos $(96,4 \%)$ nos mapas de regiões; iii) padronização dos mapas estaduais, cujas unidades morfográficas homogêneas (polígonos) são o elo comum entre os cinco produtos.

Em termos gerais, a morfografia foi o aspecto analisado que contabilizou a maior diversidade de variáveis visuais utilizadas. Embora tenham sido verificadas semelhanças na representação, sobretudo em mapas cujas metodologias seguiram influência de uma mesma escola, cabe ressaltar que essa grande variedade reforça uma problemática central da cartografia geomorfológica em relação à sistematização de legendas. Nesse sentido, os resultados demonstrados pelas tabulações corroboram com as discussões apresentadas desde a década de 1960 (COLTRINARI, 2011; VERSTAPPEN, 2011; DRAMIS et al., 2011; OTTO et al., 2011), onde a pluralidade de escalas, ênfases e objetivos, contextos geomorfológicos e níveis de detalhamento pretendidos expõem a complexidade e dificuldade de padronizar a representação. 
Figura 4 - Análise da representação da morfometria REPRESENTAÇÃO DA MORFOMETRIA
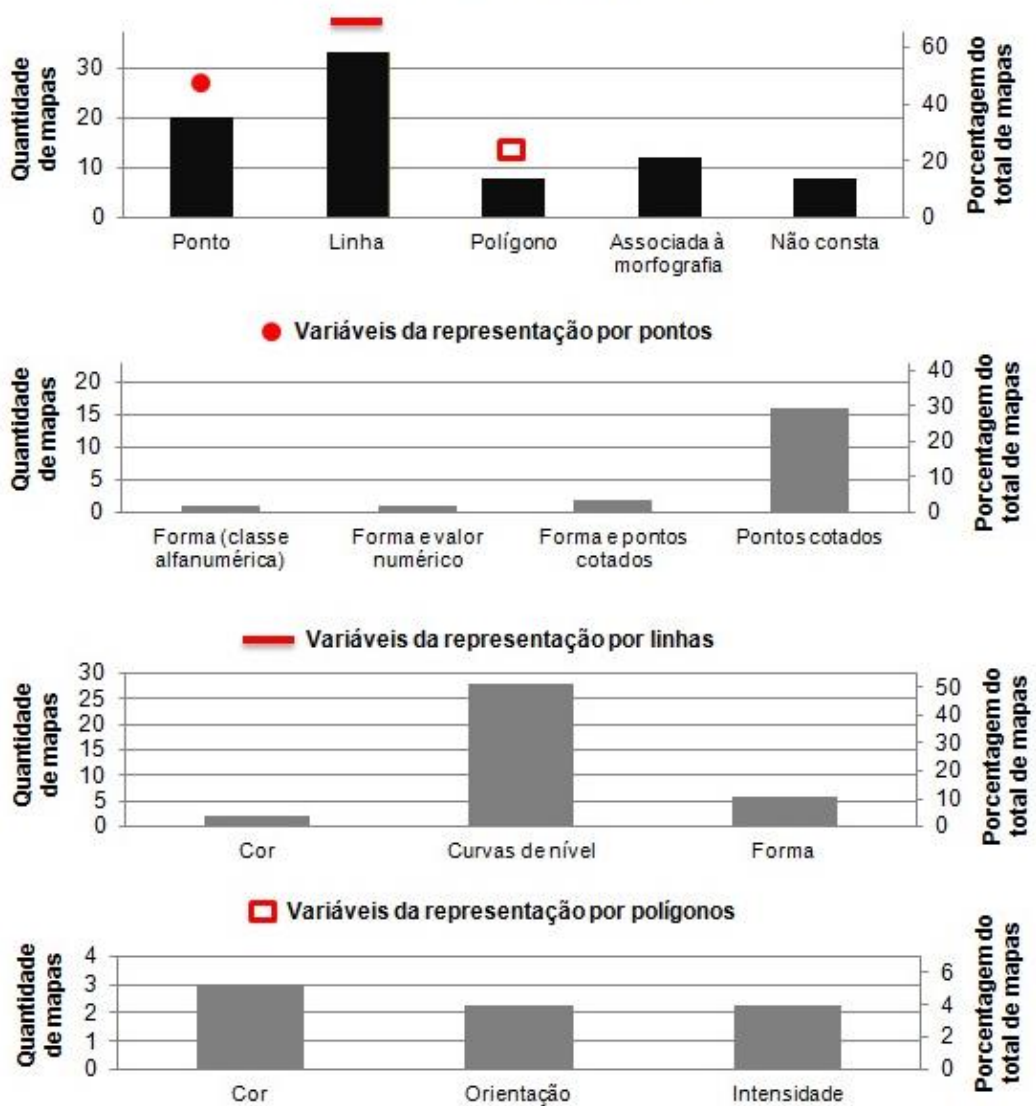

Fonte: Os autores (2021).

Os outros 59,7\% dos mapas simbolizaram a morfogenêse de modo associativo (quando há relação direta) ou implícito (quando há relação indireta) a outros aspectos geomorfológicos, com predomínio da morfografia $(45,6 \%)$. Conforme constatado, essa associação com a morfografia foi realizada principalmente pela variável cor, seguindo as mesmas recomendações temáticas supracitadas, o que facilita a leitura no mapa. Exemplos são os mapas da Austrália (ANAND; BROEKERT, 2004), Espanha (GARCÍA et al., 2005), Itália (SGN, 1994; AUCELLI et al., 2013) e de Mendoza na Argentina (ABRAHAM, 1996).

Em situação oposta à morfografia, o aspecto morfogenético foi o que apresentou maior uniformidade de representação (Figura 6). Do total de mapas, 40,3\% indicaram a morfogênese com uso de polígonos, dos quais $35 \%$ a partir da variável cor, não havendo registro de pontos e linhas. Desde as primeiras propostas que buscaram a sistematização de legendas, como Demek (1972), até as recentes, como Gustavsson et al. (2006), há uma concordância em relação à representação da morfogênese (comumente associada aos processos atuantes) por cores com feição de área. Com exceção dos mapas poloneses, que aplicaram cores específicas conforme proposta de Klimaszewski (1963a), todos os demais mapas que enfatizaram a morfogênese, por exemplo, representaram a gênese tectônica ou endogenética em vermelho, a fluvial em verde, glacial em roxo, marinha ou lacustre em azul, denudacional em laranja e eólica ou agradacional em amarelo.

Em muitos mapas, no entanto, a morfogênese foi associada à morfografia sem utilização de cores, constando somente na legenda como título ou subtítulo de um agrupamento de feições. Embora tenha sido considerada uma relação associativa, essa forma de representação secundariza a morfogênese, já que inviabiliza a assimilação direta pelo mapa principal e torna necessária a consulta constante à legenda. Dentre os mapas analisados, pode-se citar como exemplos os mapas da região de Prahova na Romênia (GRECU, 2009), região do central do Saara na Líbia (PEREGO et al., 2011), Península de Salento na Itália (FORTE; PENNETTA, 2007) e Rússia (NSU, 2018).

Em outros casos, a assimilação da morfogênese depende da interpretação por parte do leitor de aspectos geomorfológicos afins, sendo definida como relação implícita. Para os mapas estaduais, por exemplo, 
com exceção de São Paulo (que teve representação associativa), todos os demais indicaram implicitamente a morfogênese a partir das unidades morfológicas, cuja descrição genética consta apenas nos relatórios ou publicações. Já o mapa do Monte Amba Aradam, na Etiópia (COLTORTI et al., 2009), foi o único a apresentar a morfogênese implícita à morfocronologia.

Figura 5 - Análise da representação da morfografia
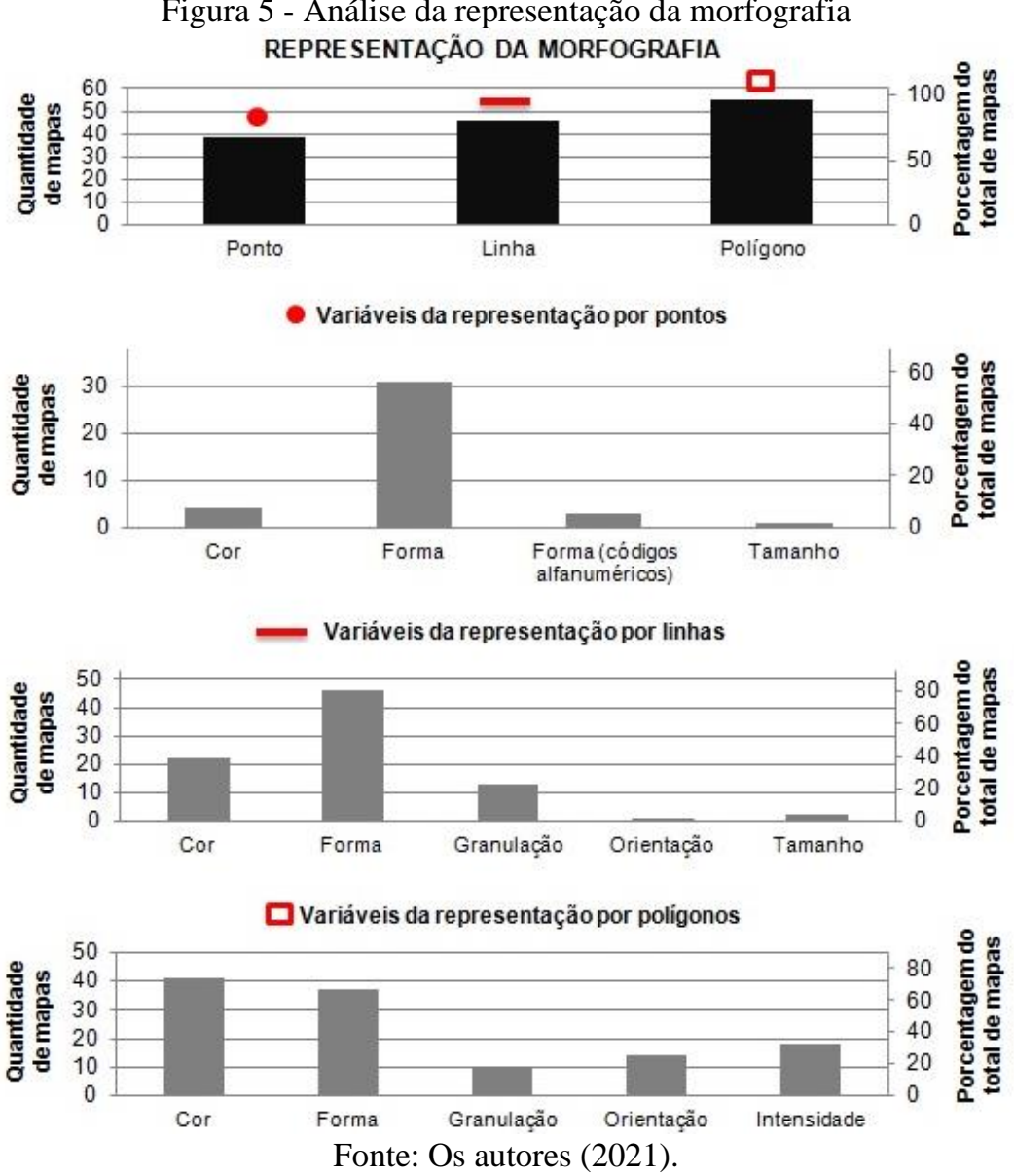

Figura 6 - Análise da representação da morfogênese.

REPRESENTAÇÄO DA MORFOGÊNESE
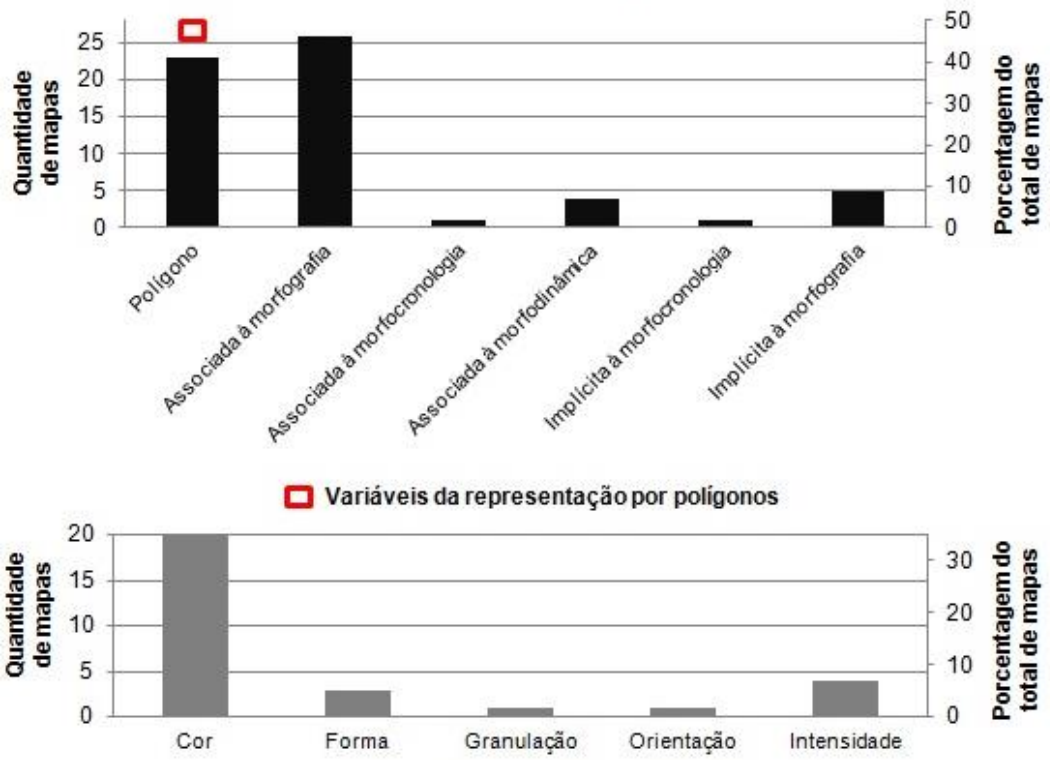

Fonte: Os autores (2021).

Sobremaneira, esses resultados demonstraram que, independentemente da escala ou do ano de publicação, a representação morfogenética foi a mais padronizada dentre os aspectos geomorfológicos 
analisados individualmente, ainda que muitas divergências tenham sido verificadas. Os mapas nacionais (52\%) tiveram número maior de representações da morfogênese por polígonos em relação aos mapas de regiões $(35,7 \%)$, por exemplo.

Referente à simbolização da morfodinâmica nos mapas geomorfológicos, destaca-se que $43,9 \%$ do conjunto total contém a representação de processos atuantes, seja por pontos, linhas ou polígonos, 36,8\% possuem representações associativas ou implícitas e 19,3\% não apresentam qualquer indicação morfodinâmica (Figura 7). A variável visual mais utilizada foi a forma, sendo representada por pontos em $36,8 \%$ dos mapas com símbolos que ilustram feições e processos, muitas vezes categorizados em ativos e inativos e agrupados na legenda de acordo com gênese comum. Apesar da diversidade, foram notadas semelhanças nos símbolos adotados em mapas europeus, como deslizamentos, escarpas erosivas, corridas de detritos e ravinas.

Figura 7 - Análise da representação da morfodinâmica.
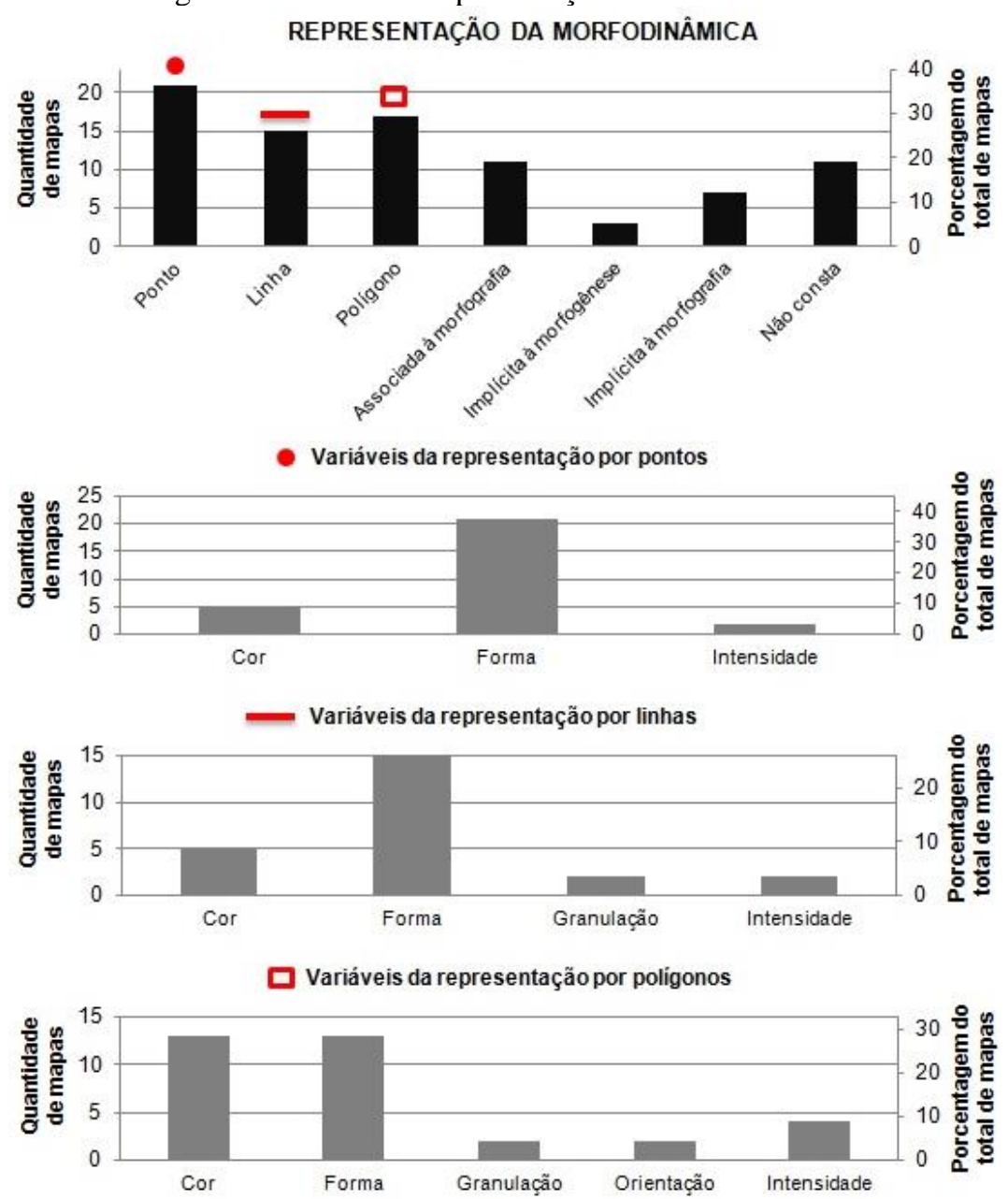

Fonte: Os autores (2021).

A inclusão de elementos morfodinâmicos mostrou-se condicionada à escala dos produtos. Assim, mapas de grande escala são favorecidos pelo nível de detalhamento cartográfico que possibilita a espacialização de fenômenos pontuais, enquanto mapas de pequena escala têm o desafio de generalizar tais informações. Isso, somado à complexa dinâmica têmporo-espacial do relevo, se reflete na pluralidade de variáveis empregadas para a caracterização morfodinâmica.

A quantificação individualizada por categoria elucida essa tendência: $21,7 \%$ dos mapas nacionais não possuem representação morfodinâmica, enquanto apenas 3,6\% dos mapas de regiões não registraram informações relacionadas. Nos mapas estaduais, todos com escala inferior a 1:250.000, novamente São Paulo (ROSS; MOROZ, 1997) foi a exceção, já que os demais não indicaram tal aspecto. Apesar das ponderações em relação à limitação de escala, destaca-se que no contexto geral cinco mapas com escalas inferiores a 1:100.00 possuem representação da morfodinâmica (Alemanha, Croácia, República Tcheca, Mendoza na Argentina, e Península de Salento na Itália) e outros cinco possuem, ao menos, representação associativa. A 
escala é, portanto, um fator desfavorável, mas não excludente.

O último aspecto geomorfológico analisado, morfocronologia, foi o de menor representatividade explicitada diretamente nos mapas, com 12,3\% do total. Embora a morfodinâmica tenha registrado uma ausência maior, de 19,2\% contra 17,5\% da morfocronologia, o diferencial está nas representações associativas ou implícitas, que contabilizaram 70,1\% (Figura 8). Esse resultado é justificado em função das notórias dificuldades de se atribuir idades, sejam absolutas ou relativas, às formas de relevo e sua consequente representação associada aos outros elementos constituintes de um mapa geomorfológico.

Figura 8 - Análise da representação da morfocronologia. REPRESENTAÇÃO DA MORFOCRONOLOGIA
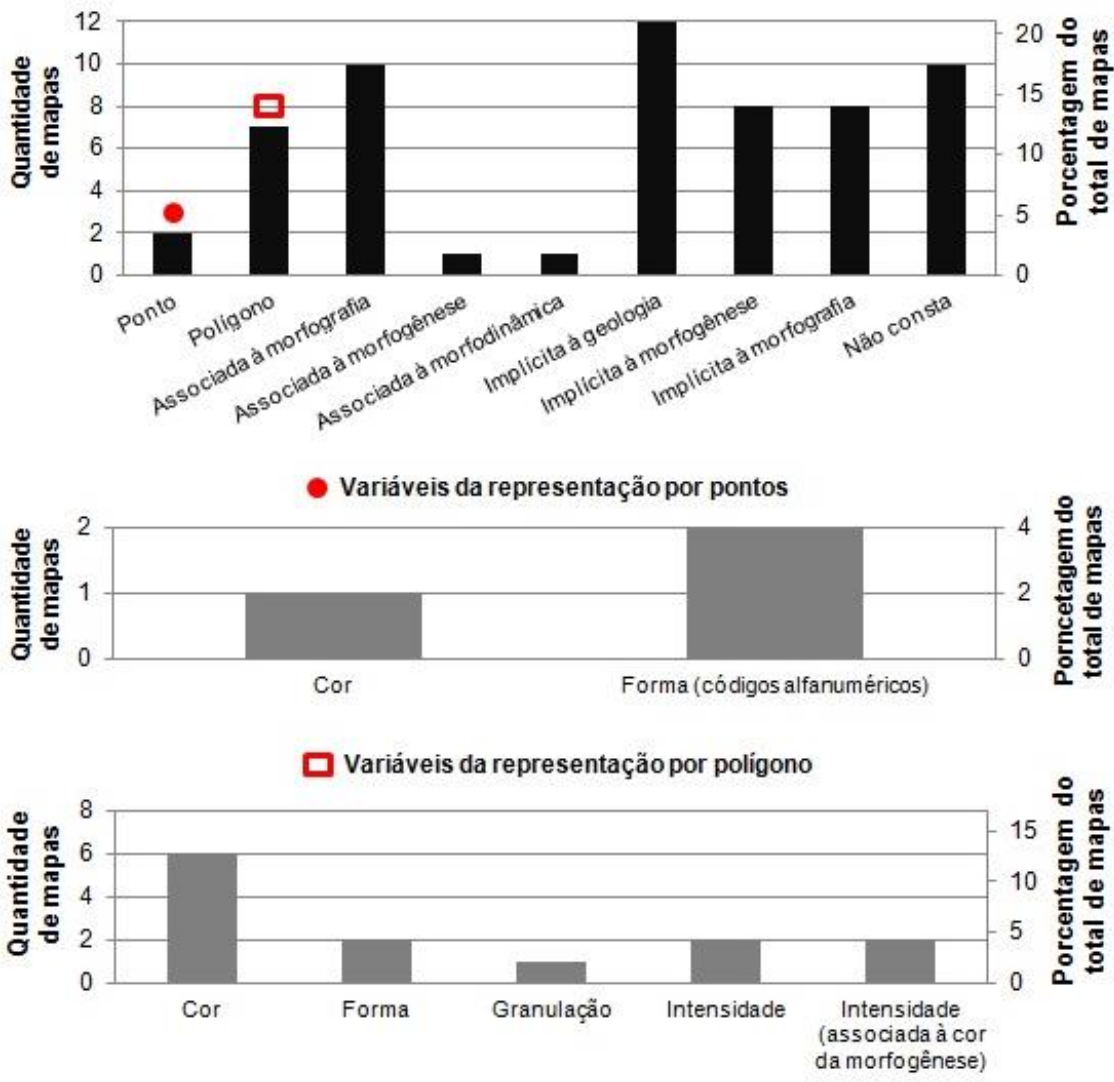

Fonte: Os autores (2021).

Na maioria dos mapas analisados a morfocronologia aparece de modo implícito, sendo necessário o conhecimento geomorfológico prévio para inferir relações temporais, o que torna a análise cronológica (ainda mais) subjetiva e imprecisa. Em 21\% dos mapas a morfocronologia foi implicitamente vinculada à geologia, principalmente às unidades litológicas, o que pode causar interpretação dúbia acerca da idade das formações rochosas e das formas de relevo, como apresentado no mapa do Parque Nacional Lagonegrese, na Itália (GIANO, 2016), da Serra do Montejunto, em Portugal (FONSECA, 2011), e da Alta Ribagorza, na Espanha (CÍA; ANDRÉS, 2008).

A representação implícita à morfogênese e morfografia, que constaram em 14\% mapas, embora também evoquem interpretações dedutivas por parte do leitor ao menos não causam confusão cronológica com a idade do substrato. Essa associação se mostrou facilitada pela atribuição qualitativa na legenda, ou seja, quando a morfocronologia aparece implícita às adjetivações de unidades morfográficas ou morfogenéticas. $\mathrm{O}$ mapa da Península de Juan Mazía, no Chile (MURO et al., 2015), por exemplo, apresenta na legenda a diferenciação de terraços marinhos em primeira, segunda, terceira e quarta ordem, o que caracteriza uma relação implícita à cronologia relativa.

Mesmo para os mapas que representaram a morfocronologia com pontos ou polígonos, ainda sim foi verificada associação direta com a morfografia ou morfogênese. Exemplo é o mapa do Equador (ALMEIDA et al., 1979), cujos polígonos com variação de cor, forma ou intensidade são compartilhados à representação de unidades de sistemas morfogenéticos. Essas constatações reafirmam o caráter dependente da indicação 
cronológica do relevo nos produtos cartográficos.

A análise categorizada apontou a semelhança entre a quantificação para mapas nacionais e de regiões, com divergência somente para a classe "implícita à geologia", que foi três vezes maior para os mapas de regiões. Os estaduais, mais uma vez, demonstraram divergência com o conjunto externo e padronização interna: todos os cinco mapas evidenciaram a morfocronologia implícita à morfografia, onde a interpretação regional da cronologia aparece somente nos relatórios descritivos à parte.

Do conjunto total de mapas, algumas propostas de representação morfocronológica obtiveram destaque: no mapa da República Tcheca (DEMEK et al., 2009), a cronologia foi atribuída, na legenda, para todos os objetos morfográficos, morfogenéticos ou morfodinâmicos ("T" para terciário, "H" para holoceno e "Q" para quaternário); no mapa holandês (KOOMEN; MAAS, 2004), a indicação da idade foi vinculada às próprias unidades morfológicas em extensa legenda acoplada ao mapa principal; no mapa russo da bacia de Pechora (NIKOLSKAYA et al., 2002) foram atribuídas ordens, em níveis ou gerações, para morainas, terraços e cristas glaciotectônicas, utilizando-se de polígonos com variação de cor; por fim, no mapa das Montanhas Dumitor em Montenegro (ANNYS et al., 2014) foram incluídas datações de morainas representativas distribuídas pela área de estudo.

Figura 9 - Análise de informações adicionais apresentadas nos mapas.

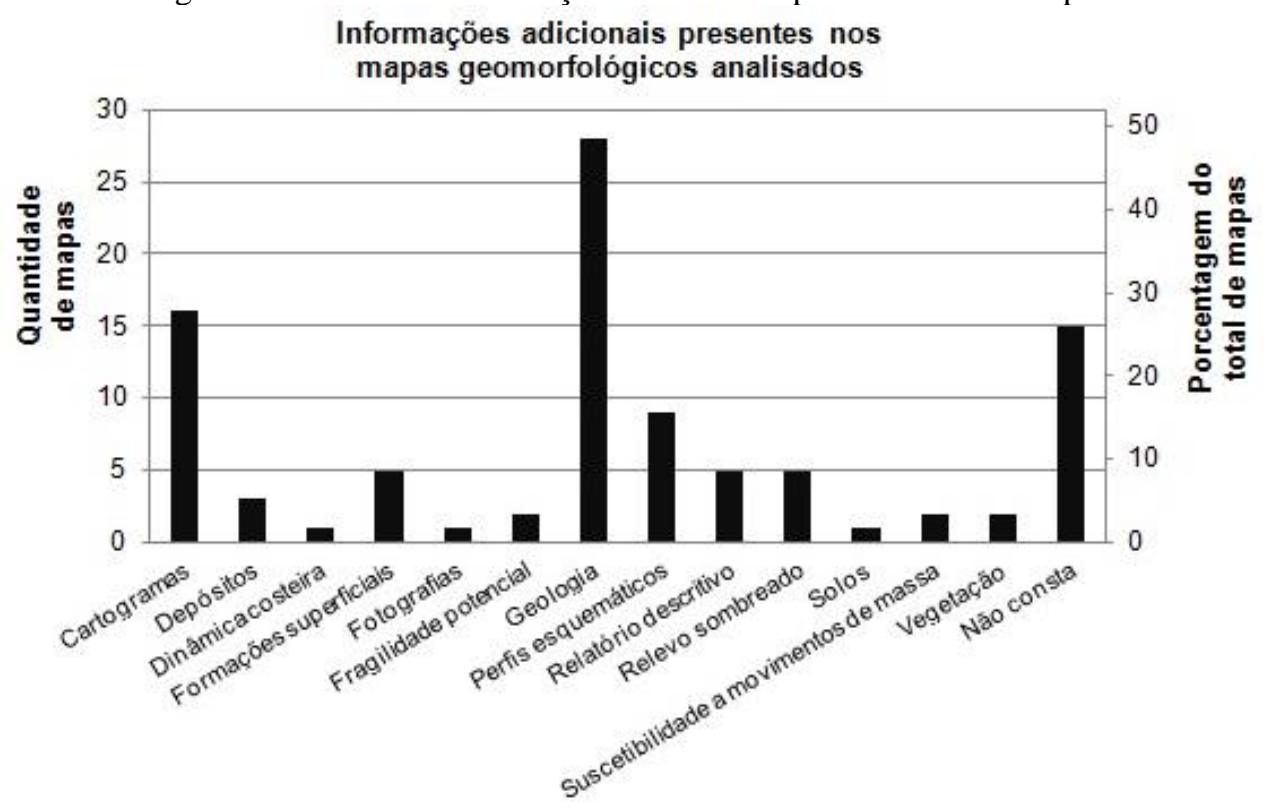

Fonte: Os autores (2021).

Além dos aspectos geomorfológicos, foram analisados os elementos acessórios presentes nos mapas, à parte da representação principal, compreendidos como informações adicionais. Conforme quantificação apresentada pela Figura 9, 26,3\% dos documentos consultados não possuem quaisquer elementos complementares, enquanto a geologia foi evidenciada em quase metade dos mapas $(49,1 \%)$, o que denota a importância dada às formações rochosas como fato essencial para a interpretação do relevo. Cabe destacar que muitos mapas incluíram a litologia como tópico do próprio mapa principal, o que eleva consideravelmente esse percentual. Dois mapas de regiões apresentaram a litologia como aspecto de ênfase: região da Basilicata, na Itália (BENTIVENGA et al., 2015), e Alta Ribagorza, na Espanha (CÍA; ANDRÉS, 2008).

O segundo elemento de maior evidência destacada foi a inserção de cartogramas temáticos (28\%). A análise permitiu avaliar que os cartogramas despontam como solução para a inclusão de informações quando o mapa principal contabiliza número excessivo de objetos cartografados, o que dificulta a leitura do produto. Nesse quesito, o mapeamento italiano (SGN, 1994) foi o que apresentou maior número e variedade de informações, contemplando geologia, declividade, modelos de relevo sombreado em perspectiva 3D, unidades morfológicas generalizadas e dados climáticos. Outro elemento que se destacou foram os perfis esquemáticos, com 15,7\%, que trazem uma perspectiva em duas dimensões e possibilitam correlação visual ilustrativa entre as formas, o substrato e, em alguns casos, de níveis de paleosuperfícies: Austrália (ANAND; BROEKERT, 2004) e Espanha (GARCÍA; CERDÁN, 2006). 
Quanto à análise das variáveis visuais de Bertin (1967) (Figura 2) empregadas nos mapas geomorfológicos, destaca-se que as mais utilizadas foram as cores e as formas, constando na maioria dos mapas conjuntamente: cores para distinguir morfogênese e formas para simbolizar feições e processos, por exemplo. A terceira variável visual de maior aplicação foi a intensidade, principalmente como critério de subdivisão para agrupamentos de determinado aspecto geomorfológico, já que possui a propriedade de ordenação. Na sequência, verificou-se que as variáveis orientação e granulação foram utilizadas de modo secundário às cores, formas e intensidades e também de modo auxiliar (sobrepostas). Por fim, constatou-se que a variável tamanho foi a de menor representatividade dentre todas as analisadas, contando em apenas três mapas.

\section{CONCLUSÃo}

A análise de distintos mapas geomorfológicos em nível mundial evidenciou que há uma variedade de propostas (conforme o local e conforme a escala) e que, por esse motivo, a padronização almejada desde a década de 1950 não se consolidou na prática. Há, no entanto, elementos comuns em muitos mapas, desde as questões conceituais até a simbolização. Concluiu-se que os mapas nacionais possuem sofisticados sistemas de legenda, os mapas de regiões podem atender objetivos específicos e que os mapas estaduais priorizam grandes unidades morfográficas, tornando implícitas as demais informações do relevo.

Na perspectiva geomorfológica, verificou-se que, do conjunto de 57 mapas analisados, pouco mais da metade $(56 \%)$ dos documentos obtiveram êxito ao representar todos os aspectos que devem compor um mapa geomorfológico. Individualmente, a morfogênese $(61,4 \%)$ e a morfografia $(52,6 \%)$ foram os elementos enfatizados na maioria dos mapas avaliados. Na perspectiva temática, constatou-se que as variáveis visuais mais empregadas em mapas geomorfológicos são cores e formas e também que o processo de comunicação cartográfica é comumente prejudicado pelo excesso de informações a serem representadas.

Ressalta-se, portanto, que o nível de abstração dos fatos geomorfológicos, num mapa, varia conforme as concepções e escalas têmporo-espaciais do projeto, conforme os conceitos teóricos adotados e conforme as especificidades do relevo local, o que justifica as dificuldades de replicação de sistemas de legendas.

Além disso, o trabalho realizado reforçou a identidade morfográfica dos mapas geomorfológicos brasileiros. Considerando as especificidades teórico-metodológicas da cartografia geomorfológica e as dificuldades de padronização, a análise de mapeamentos prévios configura etapa importante para caracterizar as escolas geomorfológicas locais e, ao mesmo tempo, subsidiar novas propostas - abrangentes e integradoras, tal como o Sistema Brasileiro de Classificação do Relevo. O grande desafio é conciliar a multiplicidade de informações e conceitos, as características e particularidades regionais e a representação simplificada e replicável num sistema de legenda unificado.

\section{Agradecimentos}

Os autores agradecem à Coordenação de Aperfeiçoamento de Pessoal de Nível Superior (CAPES) pela bolsa de fomento de nível doutorado, concedida por meio do Programa de Pós-Graduação em Geografia da Universidade Federal do Paraná (PPGGEO-UFPR), e ao Conselho Nacional de Desenvolvimento Científico e Tecnológico $(\mathrm{CNPq})$, pela disponibilização dos recursos financeiros que contribuíram com a realização do trabalho e os levantamentos de campo, por meio dos projetos "Mapeamento Geomorfológico do Estado do Paraná apoiado em análise digital do relevo, Processo no 456244/2014-0, Apoio a Projetos de Pesquisa / MCTI/ CNPQ/Universal 14/2014 - Faixa A" e "Desenvolvimento metodológico e aplicações modelagem digital do terreno no mapeamento geomorfológico", Processo no 434343/2018-8, Apoio a Projetos de Pesquisa / MCTI/ CNPQ/Universal 28/2018 - Faixa B.

\section{Contribuição dos Autores}

Ricardo Michael Pinheiro Silveira: conceptualização, análise formal, investigação, metodologia, visualização e redação. Claudinei Taborda da Silveira: conceptualização, análise formal, recursos, supervisão, validação e redação. 


\section{Conflitos de Interesse}

Os autores declaram que não há conflitos de interesse.

\section{Referências}

ABRAHAM, E. M. Mapa geomorfológico de Mendoza. Inventario de Recursos de la Región Andina Argentina. Sistema Físico Ambiental de Cuyo - Província de Mendoza, 1996.

AB'SABER, A. N. Megageomorfologia do território brasileiro. In: CUNHA, S. B.; GUERRA, A. J. T. (Orgs.) Geomorfologia do Brasil. Rio de Janeiro, Bertrand Brasil, p. 71-106, 1998.

AB'SABER, A. N. O relevo brasileiro e seus problemas. In: AZEVEDO, A. (Org.). Brasil - a terra e o homem. 1964.

AB'SABER, A. N. Problemas do mapeamento geomorfológico no Brasil. Geomorfologia, n. 6, p. 1-16, 1969.

ALLAART, L. Combining terrestrial and marine glacial archives: A geomorphological map of the Nordenskiöldbreen forefield, Svalbard. MSc. Thesis, Norwegian University of Science and Technology, Trondheim, 2016.

ALMEIDA, G.; CORLAVÄN, N.; ORQUERA, A.; ZAVGORODNYAYA, S. Inventario cartografico de la costa ecuatoriana. Salinas, escala 1:200.000. Leyenda explicativa. Quito, 1979.

ANAND, R. R.; BROEKERT, P. (eds.) (2004). Regolith landscape evolution across Australia: A compilation of regolith-landscape case studies and landscape evolution models. Disponível em: <http://crcleme.org.au/Pubs/Monographs/RegLandEvol.html>. Acesso em: 15 jun. 2017.

ANNYS, K.; FRANKL, A.; SPALEVIĆ, V.; ČUROVIĆ, M.; BOROTA, D.; NYSSEN, J. Geomorphology of the Durmitor Mountains and surrounding plateau Jezerska Površ (Montenegro). Journal of Maps, 10:4, p. 600-611, 2014. DOI. https://doi.org/10.1080/17445647.2014.909338

ARCHELA, R. S. Contribuições da semiologia gráfica para a cartografia brasileira. Geografia (Londrina), Londrina - PR, v. 10, n.1, p. 5-11, 2001.

AUCELLI, P. P. C.; CESARANO, M.; PAOLA, G.; FILOCAMO, F.; ROSSKOPF, C. M. Geomorphological map of the central sector of the Matese Mountains (Southern Italy): an example of complex landscape evolution in a Mediterranean mountain environment. Journal of Maps, 9:4, p. 604-616, 2013. DOI. https://doi.org/10.1080/17445647.2013.840054

BADEA, L., SANDU, M. The general geomorphological map of Romania on a medium scale (1:200,000). Revue Roumaine de Géographie, n. 36, 1992.

BARBOSA, G. V.; SILVA, T. C.; NATALI FILHO, T.; DEL’ARCO, D. M.; COSTA, R. C. R. Evolução da metodologia para mapeamento geomorfológico do Projeto Radambrasil. Boletim Técnico, Série Geomorfologia. Salvador n. 1, 187 p., 1984.

BENTIVENGA, M.; CAPOLONGO, D.; PALLADINO, G.; PICCARRETA, M. Geomorphological map of the area between Craco and Pisticci (Basilicata, Italy). Journal of Maps, 11:2, p. 267-277, 2015. DOI. https://doi.org/10.1080/17445647.2014.935501

BERTIN, J. Semiologie graphique: Les diagrames, les reseaux, les cartes. Paris: Mouton, 1967.

BOTELHO. R. G. M.; PELECH, A. S. Do mapeamento geomorfológico do IBGE a um Sistema Brasileiro de Classificação do Relevo. Revista Brasileira de Geografia, Rio de Janeiro, v. 64, n. 1, p. 183-201, 2019.

BUZJAK, N.; PAHERNIK, M.; BOČIĆ, N.; FAIVRE, S. Geomorphological map of Croatia 1:100.000. 8th IAG International Conference on Geomorphology, 2013.

CABAllero, M. E. M. V.; GÓMEZ-ZOTANO, J.; OLMEDO-COBO, J. A.; PEZZI-CERETTO, M. C. Geomorphology of the Sierra Gorda karst, South Spain. Journal of Maps, 12:5, p. 1143-1151, 2016. DOI. https://doi.org/10.1080/17445647.2015.1137790

CALVO, A. B.; GONZÁLEZ, A. P. Geomorphology of the Sierra de Atapuerca and the Middle Arlanzón Valley (Burgos, Spain). Journal of Maps, 11:4, p. 535-544, 2015. DOI. 
https://doi.org/10.1080/17445647.2014.909339

CARDOSO, J. A Construção de Gráficos e Linguagem Visual. História: Questões \& Debate, Curitiba 5(8):37-58, 1984.

CHENG, W.; ZHOU, C.; CHAI, H.; ZHAO, S.; LIU, H.; ZHOU, Z.. Research and compilation of the Geomorphologic Atlas of the People's Republic of China $(1: 1,000,000)$. Journal of Geographical Sciences, 21 (1), p. 89-100, 2011. DOI. https://doi.org/10.1007/s11442-011-0831-z

CÍA, J. C.; ANDRÉS, A. J. Geomorphological map of the Alta Ribagorza (Central Pyrenees, Spain). Journal of Maps, 4:1, p. 235-247, 2008. DOI. https:/doi.org/10.4113/jom.2008.1006

COELHO, A. L. N.; GOULART, A. C. O.; BERGAMASCHI, R. B.; TEUBNER JUNIOR, F. J. Mapeamento geomorfológico do estado do Espírito Santo. Nota técnica 28. Instituto Jones dos Santos Neves, Vitória, 2012 .

COLTORTI, M.; PIERUCCINI, P.; BERAKHI, O.; DRAMIS, F.; ASRAT, A. The Geomorphological Map of Mt. Amba Aradam Southern Slope (Tigray, Ethiopia). Journal of Maps, 5:1, p. 56-65, 2009. DOI. https://doi.org/10.4113/jom.2009.1043

COLTRINARI, L. Cartografia geomorfológica detalhada: a representação gráfica do relevo entre 1950-1970. Revista Brasileira de Geomorfologia, v.12, n.3, p.121-130, 2011. DOI. http://dx.doi.org/10.20502/rbg.v12i0.265

CPRM - Serviço Geológico do Brasil. Mapas geomorfológicos do estado do Rio de Janeiro: escala $1: 250.000,2000$.

DEMEK, J. (Ed.) Manual of Detailed Geomorphological Mapping. IGU Commission for Geomorphological Mapping. Academia, Prague, 1972.

DEMEK, J.; KIRCHNER, K.; MACKOVČIN, P.; SLAVIK, P. Concept of a new general geomorphological map of the Czech Republic. Problems of Geography, n. 2-3, p. 55 -60, 2009.

DENT, B. D. Cartography: Thematic Map Design. 5. ed. New York: McGraw-Hill, 1999.

DEVOTO, S.; BIOLCHI, S.; BRUSCHI, V. M.; FURLANI, S.; MANTOVANI, M.; PIACENTINI, D.; PASUTO, A.; SOLDATI, M. Geomorphological map of the NW Coast of the Island of Malta (Mediterranean Sea). Journal of Maps, 8:1,p. 33-40, 2012. DOI. https://doi.org/10.1080/17445647.2012.668425

DINIZ, M. T. M.; OLIVEIRA, G. P.; MAIA, R. P.; FERREIRA, B. Mapeamento Geomorfológico do estado do Rio Grande do Norte. Revista Brasileira de Geomorfologia (Online), São Paulo, v. 18, n.4, p. 689701, 2017. DOI. http://dx.doi.org/10.20502/rbg.v18i4.1255

DOORNKAMP, J. C. Geomorphological mapping. In: OMINDE, S. H. (ed.) Studies in East African geography and development. Heinmann Educational Books, 1971.

DRAMIS, F.; BISCI, C. Cartografia Geomorfologica. Manuale di Introduzione al Rilevamento ed alla Rappresentazione Degli Aspetti Fisici del Territorio. Pitagora Editrice, Bologna, 1998.

DRAMIS, F.; DOMENICO, G.; ANTONELLO, C. Nature and Aims of Geomorphological Mapping. In: SMITH, M. J.; PARON, P.; GRIFFITHS, J. eds. Geomorphological Mapping: Methods and Applications, Developments in Earth Surface Processes vol 15, Elsevier, 2011.

FACCINI, F.; PICCAZZO, M.; ROBBIANO, A.; ROCCATI, A. Applied geomorphological map of the Portofino Municipal Territory (Italy). Journal of Maps, 4:1, p. 451-462, 2008. DOI. https://doi.org/10.4113/jom.2008.1023

FLORENZANO, T. G. Cartografia. In: FLORENZANO, T. G (Org). Geomorfologia: Conceitos e tecnologias atuais. São Paulo: Oficina de Textos, 2008. Cap. 4, p. 105-120.

FONSECA, A. F. Geomorphology of the Montejunto massif (Portugal). Journal of Maps, 7:1, p. 138-147, 2011. DOI. https://doi.org/10.4113/jom.2011.1131

FONSECA, A. F.; ZÊZERE, J. L.; NEVES, M. Geomorphology of the Arrábida Chain (Portugal). Journal of Maps, 10:1, p. 103-108, 2014. https://doi.org/10.1080/17445647.2013.859637 
FORTE, F.; PENNETTA, L. Geomorphological Map of the Salento Peninsula (southern Italy). Journal of Maps, 3:1, p. 173-180, 2007. DOI. https://doi.org/10.1080/jom.2007.9710836

GARCÍA, A. M. S.; GONZÁLEZ, A. M.; MARTÍN, F. N.; RINCÓN, A. S.; RODRÍGUEZ, A. S. Mapa geomorfológico de España y del margen continental. Escala 1:1.000.000. Instituto Geológico y Minero de España, 2005.

GARCÍA, J. A. R.; CERDÁN, F. P. Normas de organización de la información del Mapa Geomorfológico Nacional digital. Informe técnico, Instituto Geológico y Minero de España, 42 p., 2006.

GEILHAUSEN, M.; OTTO, J. C.; SCHROTT, L. Geomorphological map of the Pasterze landsystem. Journal of Maps, 2012. DOI. https://doi.org/10.1080/17445647.2012.708540

GERASSIMOV, I. P.; MESCHERIKOV, J. L. Morphostructure. In: FAIRBRIDGE, R. W. (Ed.). The encyclopedia of geomorphology. New York: Reinhold Book Corp., 1968.

GIANO, S. I. Geomorphology of the Agri intermontane basin (val d'Agri-Lagonegrese National Park, Southern Italy). Journal of Maps, 12:4, p. 639-648, 2016. DOI. https://doi.org/10.1080/17445647.2015.1068715

GILEWSKA, S.; KLIMKOWA, M.; STARKEL, L. The 1:500.000 Geomorphological Map of Poland. Geographia Polonica, n. 48, p. 7-25, 1982.

GRECU, F. Geomorphological Map of the Prahova Subcarpathians (Romania). Journal of Maps, 5:1, p. 108116, 2009. DOI. https://doi.org/10.4113/jom.2009.1052

GUSTAVSSON, M.; KOLSTRUP, E.; SEIJMONSBERGEN, A. C. A new symbol-and-GIS based detailed geomorphological mapping system: renewal of a scientific discipline for understanding landscape $\begin{array}{llllll}\text { development. } & \text { Geomorphology } & 77, & \text { p. } & 90-111, & 2006 .\end{array}$ https://doi.org/10.1016/j.geomorph.2006.01.026

INSTITUTO BRASILEIRO DE GEOGRAFIA E ESTATÍSTICA (IBGE). Manual Técnico de Geomorfologia. $2^{a}$ ed. Rio de Janeiro: Instituto Brasileiro de Geografia e Estatística, 175 p., 2009.

JENSEN, E. H. Geomorphological map of Eskifjörður. Icelandic Meteorological Office, 2002.

KARYMBALIS, E.; GAKI-PAPANASTASSIOU, K.; TSANAKAS, K.; FERENTINOU, M. Geomorphology of the Pinios River delta, Central Greece. Journal of Maps, 12:sup1, p. 12-21, 2016. DOI. https://doi.org/10.1080/17445647.2016.1153356

KLIMASZEWSKI, M. Detailed geomorphological maps. ITC Journal, n. 3, p. 265-271, 1982.

KLIMASZEWSKI, M. Landform list and signs used in the detailed geomorphological map. Geographical Studies, n. 46 (Problems of geomorphological mapping), p. 139-177, 1963a.

KLIMASZEWSKI, M. The principles of the geomorphological map of Poland. Geographical Studies, n. 46 (Problems of geomorphological mapping), p. 67-72, $1963 \mathrm{~b}$.

KOHLER, H. C. A Escala na Análise Geomorfológica. Revista Brasileira de Geomorfologia, Volume 2, n. 1, p. 21-33, 2001. DOI. http://dx.doi.org/10.20502/rbg.v2i1.5

KOOMEN, A. J. M.; MAAS, G. J. Geomorfologische Kaart Nederland (GKN). Achtergronddocument bij het landsdekkende digitale bestand. Wageningen, Alterra, Alterra Report no. 1039, 38 p., 2004.

LAMBIEL, C.; MAILLARD, B.; KUMMERT, M.; REYNARD, E. Geomorphology of the Hérens valley (Swiss Alps). Journal of Maps, 12:1, p. 160-172, $2016 . \quad$ DOI. https://doi.org/10.1080/17445647.2014.999135

LATRUBESSE, E. M.; CARVALHO, T. M. Geomorfologia do Estado de Goiás e Distrito Federal. GOIÁS (Estado). Secretaria de Indústria de Comércio. Superintendência de Geologia e Mineração. Goiânia, 2006.

LESER, H.; STÄBLEIN, G. (eds.). Geomorphologische Kartierung. Richtlinien zur Herstellung geomorphologischer Karten 1:25000. Berliner Geogr. Abh., Sonderheft: 25 S.; Berlin, 1975.

MAY, J. H. A geomorphological map of the Quebrada de Purmamarca, Jujuy, NW Argentina. Journal of Maps, 4:1, 211-224, 2008. DOI. https://doi.org/10.4113/jom.2008.1019

MESCERJAKOV, J. P. Les concepts de morphostruture et de morphosculture: un nouvel instrument de l'analyse géomorphologique. Annales de Géographie, Paris, t. 77, n. 423, p. 539-552, 1968. 
MIRZAYEV, K. Geomorphological Map of Syria. Syrian Arab Republic, Department of Geological and Mineral Research, 1963.

MURO, S.; GRANDE, A.; BRAMBATI, A.; IBBA, A. Geomorphology map of the marine and transitional terraces and raised shorelines of the Península Juan Mazía, Tierra Del Fuego. Straits of Magellan - Chile. Journal of Maps, 11:5, p. 698-710, 2015. DOI. https://doi.org/10.1080/17445647.2014.970592

NIKOLSKAYA, O.; ASTAKHOV, V.; MANGERUD, J.; MATIOUCHKOV, A.; SVENDSEN, J. I. Geomorphological Map of the Pechora Basin and Adjacent Areas. Institute of Remote Sensing Methods for Geology (NIIKAM), St. Petersburg, 2002.

NIR, D. Israel - Geomorphological Map. Atlas of Israel. Survey of Israel, 1978.

NSU - Novosibirsk State University. Геоморфологическая карта СССР. Масштаб 1:16.000.000. Disponível em: <https://nsu.ru/ff166dbd0419b06e4e084bd4b97f0603>. Acesso em: 12 jul. 2018.

OLIVEIRA, F. A.; VIEIRA, C. V. Semi-detailed Geomorphological Map of Northeastern Santa Catarina State, Brazil — the Garuva Sheet. Journal of Maps, 5:1, 66-74, 2009. https://doi.org/10.4113/jom.2009.1037

OOSTEROM, A. P. Geomorphological Map of South-East Kenya. Coast Province Geoscience Research Project. Pudoc, Wageningen, 1988.

OTTO, J. C.; DIKAU, R. Geomorphologic System Analysis of a High Mountain Valley in the Swiss Alps. Zeitschrift für Geomorphologie, n. 48(3), p. 323-341, 2004.

OTTO, J. C.; GUSTAVSSON, M.; GEILHAUSEN, M. Cartography: Design, Symbolisation and Visualisation of Geomorphological Maps. In: SMITH, M. J.; PARON, P.; GRIFFITHS, J. eds. Geomorphological Mapping: Methods and Applications, Developments in Earth Surface Processes vol 15, Elsevier, 2011.

OTTO, J. C.; SMITH, M. J. Geomorphological Mapping. Geomorphological Techniques, cap. 2, seção 6, p. 1-10, British Society for Geomorphology, 2013.

PELECH, A. S.; NUNES, B. T. A.; GATTO, L. C. S.; BOTELHO, R. G. M. Considerações sobre o mapeamento geomorfológico do território brasileiro: algumas abordagens na representação regional. Revista Brasileira de Geomorfologia, v. 20, n. 3 , p. 681-690, $2019 . \quad$ DOI. http://dx.doi.org/10.20502/rbg.v20i3.1565

PERAZA, A. H. P.; DÍAZ, J. L.; SANTANA, J. R. H.; GARCÍA, A. R. M.; SEGUNDO, P. B. Geomorfología. In: HERRERO, E. A. S. Nuevo atlas nacional de Cuba. La Habana: Instituto de Geografía de la Academia de Ciencias de Cuba y el Instituto Cubano de Geodesia y Cartografía, 1989.

PEREGO, A.; ZERBONI, A.; CREMASCHI, M. Geomorphological Map of the Messak Settafet and Mellet (Central Sahara, SW Libya). Journal of Maps, 7:1, p. 464-475, 2011. DOI. https://doi.org/10.4113/jom.2011.1207

QUEIROZ NETO, J. P.; JOURNAUX, A. Carta geomorfológica de São Pedro, escala 1:50.000. Instituto de Geografia da Universidade de São Paulo, 1977.

RACZKOWSKA, Z.; ZWOLIŃSKI, Z. Digital Geomorphological Map of Poland. Geographia Polonica, 88, 2, pp. 205-210, 2015.

RODRIGUES, S. C. Cartografia e simbologia geomorfológica. Evoluindo da cartografia tradicional para o uso de simbologia digital. Revista Brasileira de Geomorfologia, v.11, n.1, p.3-10, 2010. DOI. http://dx.doi.org/10.20502/rbg.v11i1.136

ROSS, J. L. S.; MOROZ, I. C. Mapa geomorfológico do estado de São Paulo: Escala 1:500.000. Volume I e Volume II. Depto. Geografia FFLHC-USP, IPT e FAPESP, 1997.

ROSS, J. S. Registro cartográfico dos fatos geomorfológicos e a questão da taxonomia do relevo. Revista do Departamento de Geografia, v. 6, p. 17-29, 1992.

SANTOS, L. J. C.; OKA-FIORI, C.; CANALI, N. E.; FIORI, A. P.; SILVEIRA, C. T.; SILVA, J. M. F.; ROSS, J. L. S. Mapeamento geomorfológico do Estado do Paraná. Revista Brasileira de Geomorfologia, n. 2, p. 3-12, 2006. DOI. http://dx.doi.org/10.20502/rbg.v7i2.74

SEIJMONSBERGEN, A. C.; GRAAFF, L. W. S. Geomorphological mapping and geophysical profiling for 
the evaluation of natural hazards in an alpine catchment. Natural Hazards and Earth System Sciences, n. 6, p. 185-193, 2006. DOI. https://doi.org/10.5194/nhess-6-185-2006

SERGEOMIN - Servicio Geológico Minero. Mapa geomorfológico de Bolivia. Disponível em: <http://ide.sergeomin.gob.bo/hmsgm/index.html>. Acesso em: 13 jun. 2018.

SGN - Servizio Geologico Nazionale. Carta Geomorfologica d'Italia 1:50,000: Guida al rilevamento. Quaderno n. 3 del SGN, a cura del Gruppo di Lavoro per la Cartografia Geomorfologica. Istituto Poligrafico e Zecca dello Stato 42, Roma, 1994.

SHARY, P. A.; SHARAYA, L. S.; MITUSOV, A. V. Fundamental quantitative methods of land surface analysis. Geoderma 107 (1-2), p. 1-32, 2002. DOI. https://doi.org/10.1016/S0016-7061(01)00136-7

SILVEIRA, R. M. P. Cartografia Temática. $1^{\text {a }}$ ed. Curitiba: Editora Intersaberes, 2019.

SLOCUM, T., R.; MCMASTER, R. B.; KESSLER, F. C.; HOWARD, H. H. Thematic Cartography and Geovisualization. $3^{\text {a }}$ edição. Upper Saddle River, NJ: Prentice Hall, 576 p., 2009.

TRICART, J. Normes pour l'établissement de la carte géomorphologique de la France. Mem. Doc. CNRS 12, 1-267, 1970.

VERSTAPPEN, H. T. Old and New Trends in Geomorphological and Landform Mapping. In: SMITH, M. J.; PARON, P.; GRIFFITHS, J. (eds.) Geomorphological Mapping: Methods and Applications, Developments in Earth Surface Processes vol 15, Elsevier, 2011. Cap. 2. p. 13-35.

VERSTAPPEN, H. T. Remote Sensing in Geomorphology. Elsevier, Amsterdam, 1977.

VERSTAPPEN, H. T.; HOSCHTITZKY, M.E.D. Geomorphological Map of Sri Lanka. Department of Geography ITC, Enschede, The Netherlands, 1987.

\section{Biografia do autor principal}

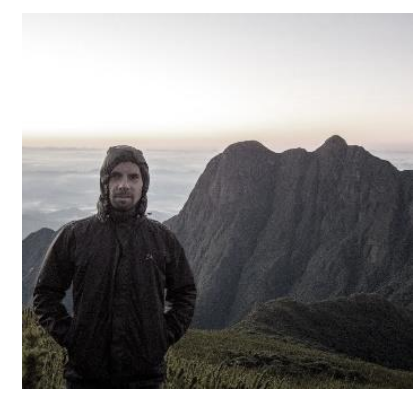

Ricardo Michael Pinheiro Silveira nasceu em Curitiba, Paraná, em 1990. PósDoutor, Doutor, Mestre e Graduado em Geografia (bacharelado e licenciatura) pela Universidade Federal do Paraná (UFPR). Atualmente é professor do Instituto Federal do Paraná (IFPR/Campus Curitiba), oferta disciplinas no Programa de PósGraduação em Geografia (UFPR), é pesquisador do Laboratório de Pesquisas Aplicadas em Geomorfologia e Geotecnologias (LAGEO/UFPR) e membro do Sistema Brasileiro de Classificação do Relevo (SBCR). Atua principalmente nas áreas de Geomorfologia (mapeamento geomorfológico, modelagem digital do relevo e movimentos de massa), Cartografia Temática, SIG e Análise Ambiental.

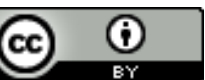

Esta obra está licenciada com uma Licença Creative Commons Atribuição 4.0 Internacional - CC BY. Esta licença permite que outros distribuam, remixem, adaptem e criem a partir do seu trabalho, mesmo para fins comerciais, desde que lhe atribuam o devido crédito pela criação original. 